Supporting Information

for

\title{
Fluorescence Toggling Mechanism of Photochromic \\ Phenylhydrazones: N-N Single Bond Rotation-Assisting E/Z \\ Photoisomerization Differs from Imine
}

Gang Wang, ${ }^{\ddagger}$ Yazhen Li, ${ }^{\ddagger}$ Tingting Song, Congdi Shang, Jiawei Yang, Makroni Lily, Yu Fang,
Fengyi Liu 


\section{Table of Contents}

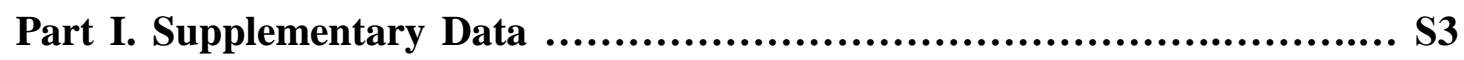

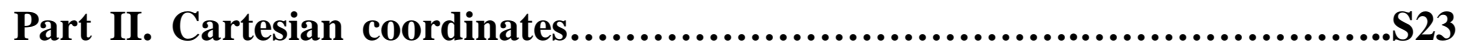




\section{Part I. Supplementary data}

Table S1. Calculated absorption and emission wavelengths of DMA-PHA- $Z$ and DMA-PHA- $E$ in toluene and acetonitrile using the PCM methodology with state-specific (SS) solvation correction. Experimental data were obtained from reference 27.

\begin{tabular}{|c|c|c|c|c|c|}
\hline & Solvents & & Basis set & $\lambda_{\mathrm{abs}}(\mathrm{nm})$ & $\lambda_{\mathrm{em}}(\mathbf{n m})$ \\
\hline \multirow{6}{*}{ DMA-PHA-Z } & & Exp. & & 395 & 525 \\
\hline & Toluene & & 6-31G(d,p) & 368 & 481 \\
\hline & & & $6-311+G(d, p)$ & 378 & 503 \\
\hline & & Exp. & & $\sim 375$ & $\sim 570$ \\
\hline & Acetonitrile & & 6-31G(d,p) & 366 & 560 \\
\hline & & & 6-311+G(d,p) & 376 & 590 \\
\hline \multirow{3}{*}{ DMA-PHA-E } & & Exp. & & 343 & \\
\hline & Toluene & & 6-31G(d,p) & 330 & \\
\hline & & & $6-311+G(d, p)$ & 343 & \\
\hline
\end{tabular}



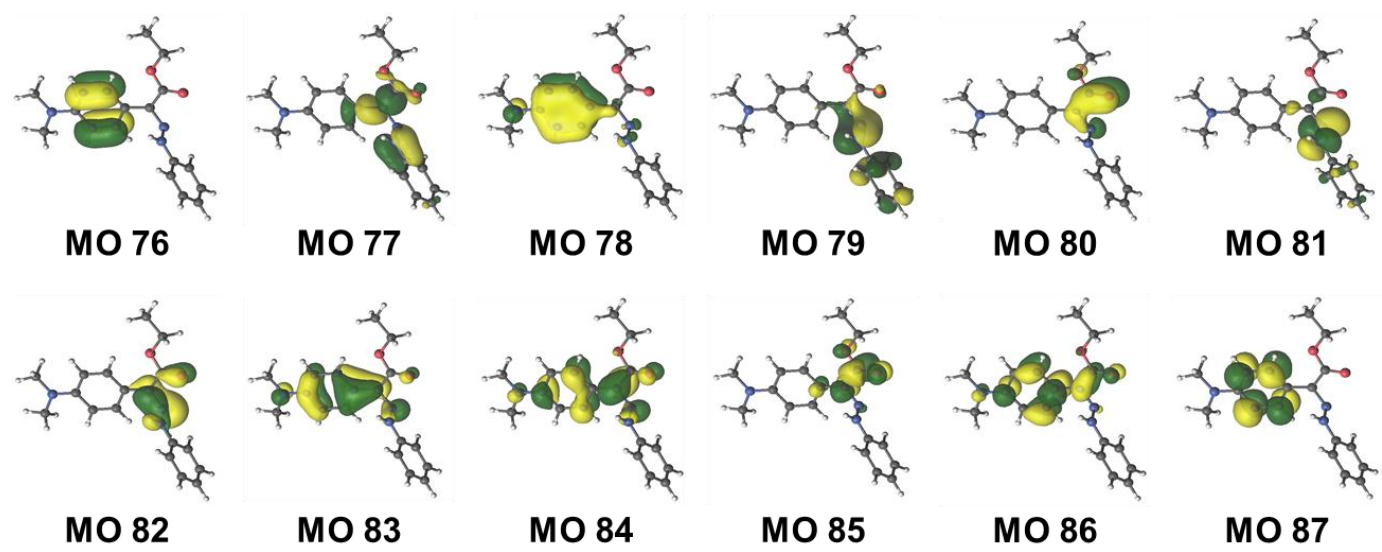

Figure S1. The active orbitals of DMA-PHA, CAS(16e,12o), used in the MS-CASPT2/6-31G(d,p) calculations.
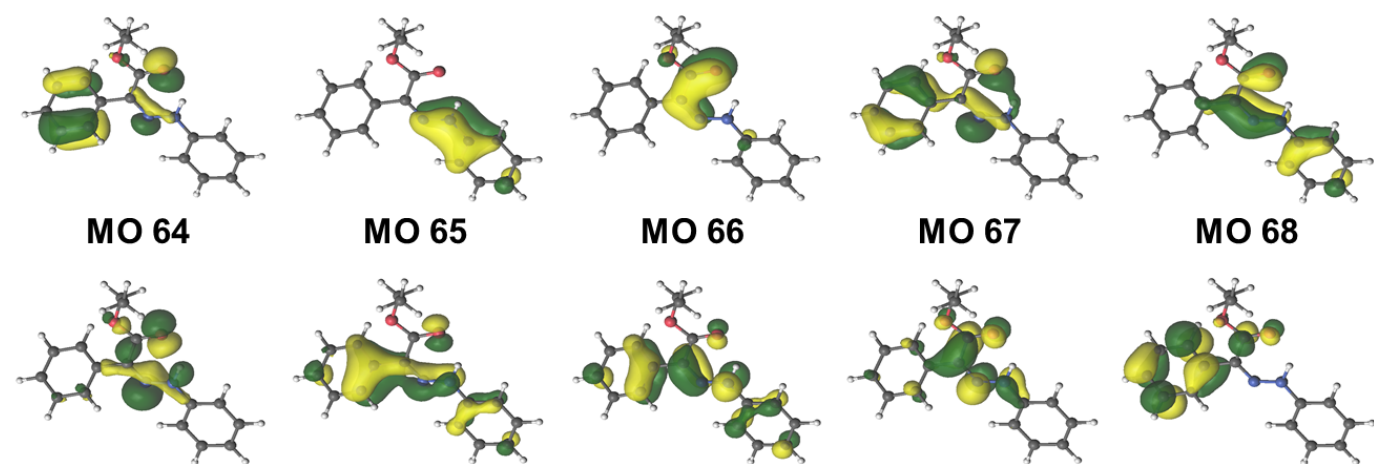

MO 72

MO 68

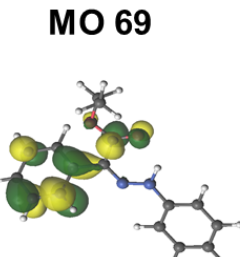

MO 70

MO 71

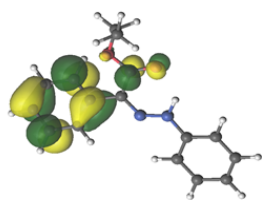

MO 73

MO 74

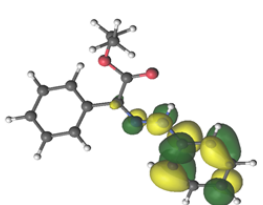

MO 75

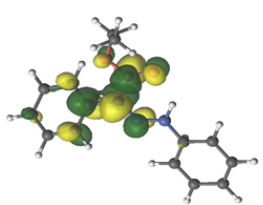

MO 76

Figure S2. The active orbitals of PHA, CAS(16e,13o), used in the MS-CASPT2/6-31G(d,p) calculations. 

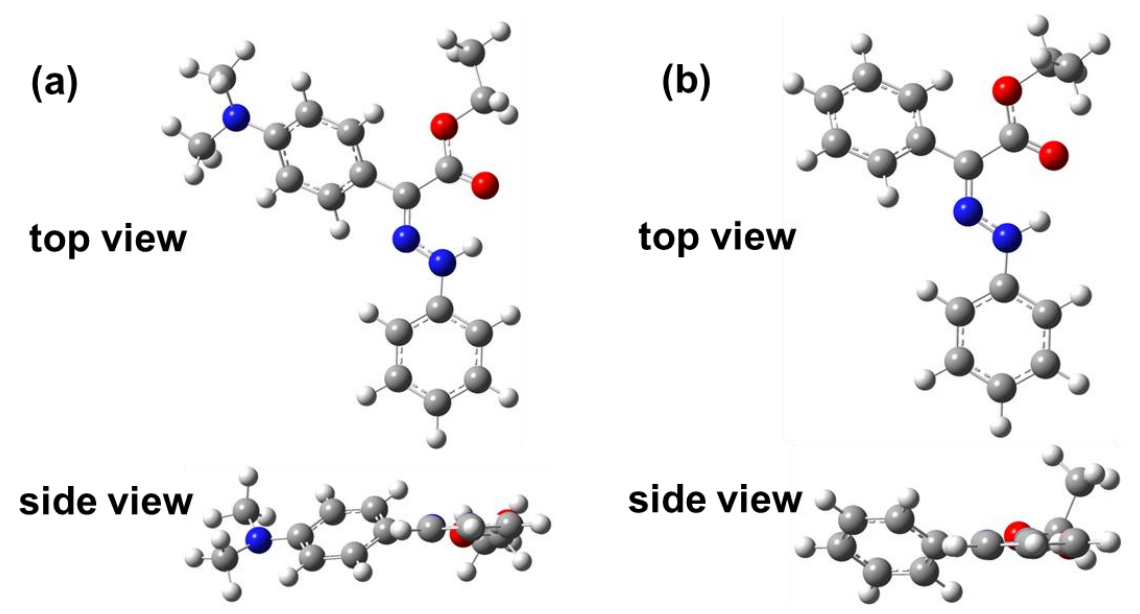

Figure S3. Optimized geometrical structures of DMA-PHA-Z (a) and PHA-Z (b) in toluene at the $\mathrm{S}_{0}$ minimum.

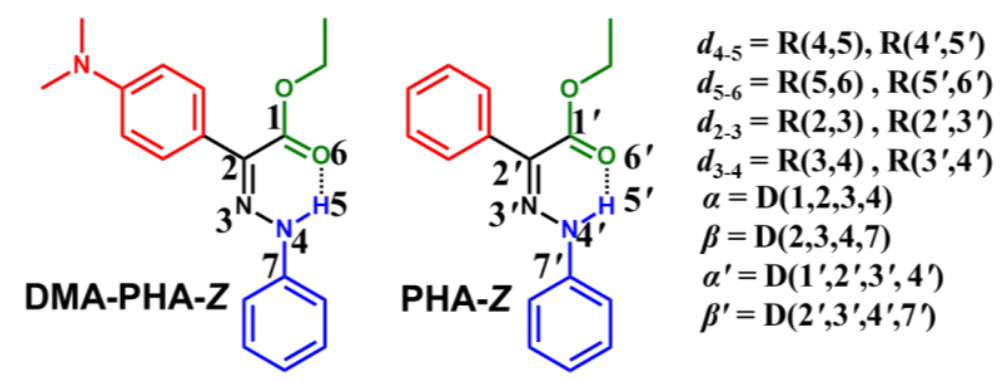

Table S2. Key geometry parameters (bond distances in angstroms and dihedral angles in degree) for the $\mathrm{S}_{0}$ and $\mathrm{S}_{1}$ Minima of DMA-PHA and PHA in toluene.

\begin{tabular}{clcccccc}
\hline Structure & $\boldsymbol{d}_{\mathbf{4 - 5}} / \AA$ & $\boldsymbol{d}_{\mathbf{5 - 6}} / \AA$ & $\boldsymbol{d}_{\mathbf{2 - 3}} / \AA$ & $\boldsymbol{d}_{\mathbf{3 - 4}} / \AA$ & $\boldsymbol{\alpha}\left(\boldsymbol{\alpha}^{\prime}\right) /^{\circ}$ & $\boldsymbol{\beta}\left(\boldsymbol{\beta}^{\prime}\right) /^{\circ}$ \\
\hline Crystal & 0.839 & 1.985 & 1.304 & 1.333 & -1.9 & -178.5 \\
& $\mathbf{S}_{\mathbf{0}}$-min-Z & 1.017 & 1.878 & 1.301 & 1.317 & 1.0 & -178.7 \\
DMA-PHA & $\mathbf{S}_{\mathbf{1}}$-min-Z & 1.032 & 1.734 & 1.372 & 1.331 & -3.0 & 179.0 \\
& $\mathbf{S}_{\mathbf{1}}$-min-prep & 1.015 & 3.262 & 1.404 & 1.321 & 93.4 & 177.2 \\
\hline & Crystal & 0.881 & 1.997 & 1.308 & 1.327 & 1.2 & -178.5 \\
& $\mathbf{S}_{\mathbf{0}}$-min & 1.018 & 1.881 & 1.301 & 1.313 & 1.5 & -179.9 \\
& $\mathbf{S}_{\mathbf{1}}$-min-prep & 1.014 & 3.203 & 1.394 & 1.321 & 93.5 & 178.1 \\
\hline
\end{tabular}




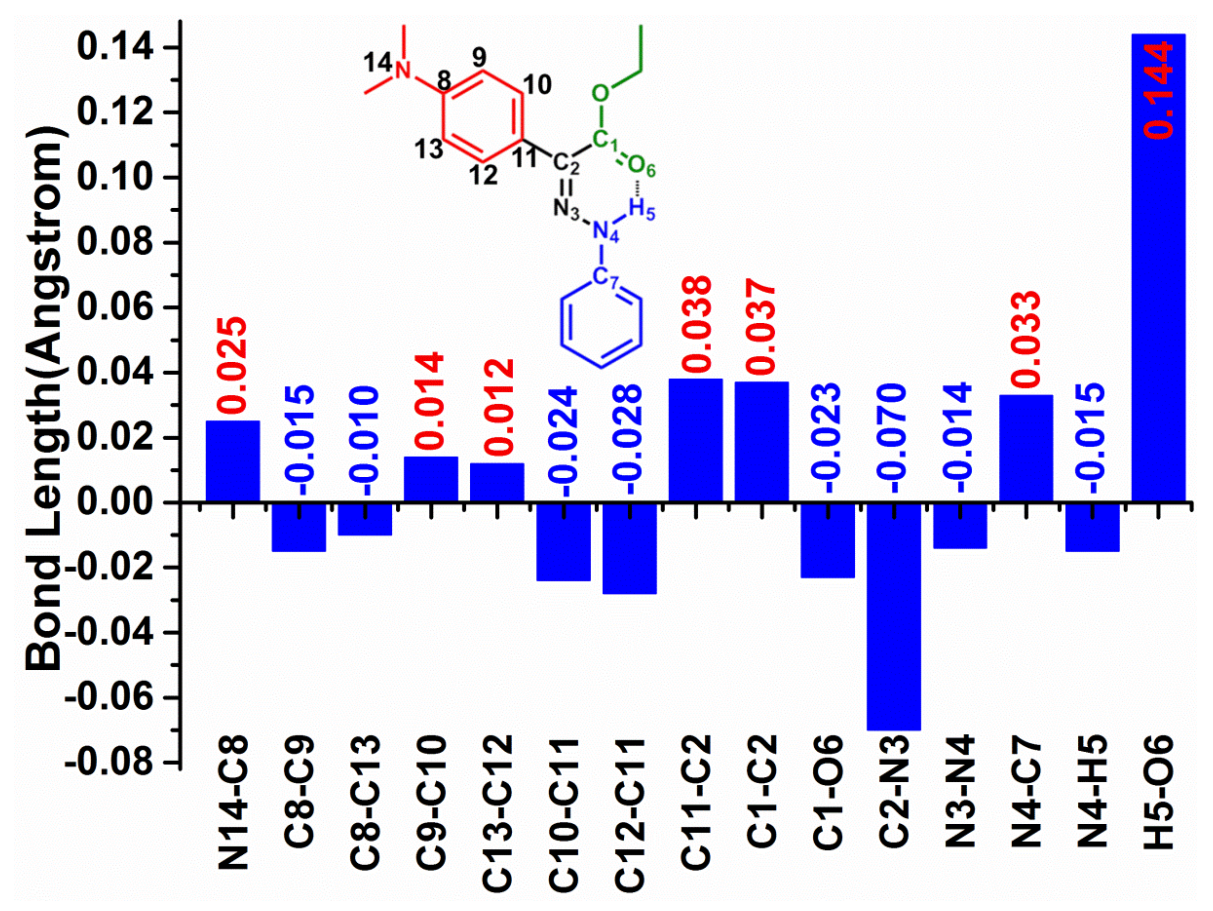

Figure S4. The difference values that the important bond length of key geometries of DMA-PHA- $Z$ at the $S_{0}$ minimum point subtracts its corresponding bond length at the local $S_{1}$ minimum optimized at (TD-)M06-2X/6-31G(d,p) level in toluene, the values are given in angstroms. 

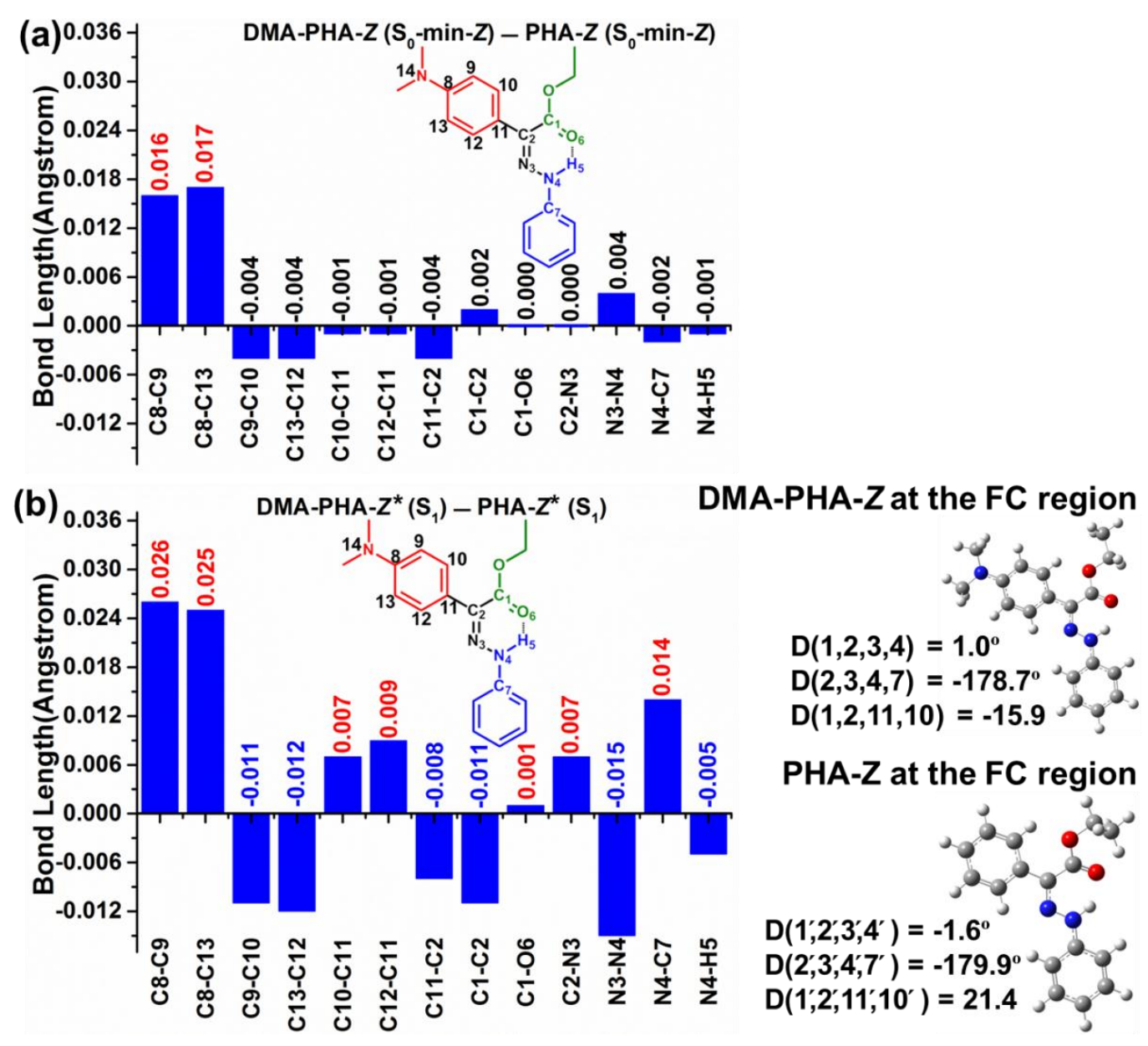

Figure S5. (a) The difference values that the important bond length of key geometries of DMA-PHA- $Z$ subtracts the corresponding bond length of PHA- $Z$ at the $\mathrm{S}_{0}$ minimum point optimized at M06-2X/6-31G(d,p) level in toluene, the values are given in angstroms. (b) The difference values that the important bond length of key geometries of DMA-PHA- $Z$ subtracts the corresponding bond length of PHA- $Z$ at the Franck-Condon region on the $S_{1}$ state using restrained $\alpha$ and $\beta$ dihedral angle optimizations at M06-2X/6-31G(d,p) level in toluene, the values are given in angstroms, the correspondingly optimized geometries of DMA-PHA- $Z$ and PHA- $Z$ in the right side. 


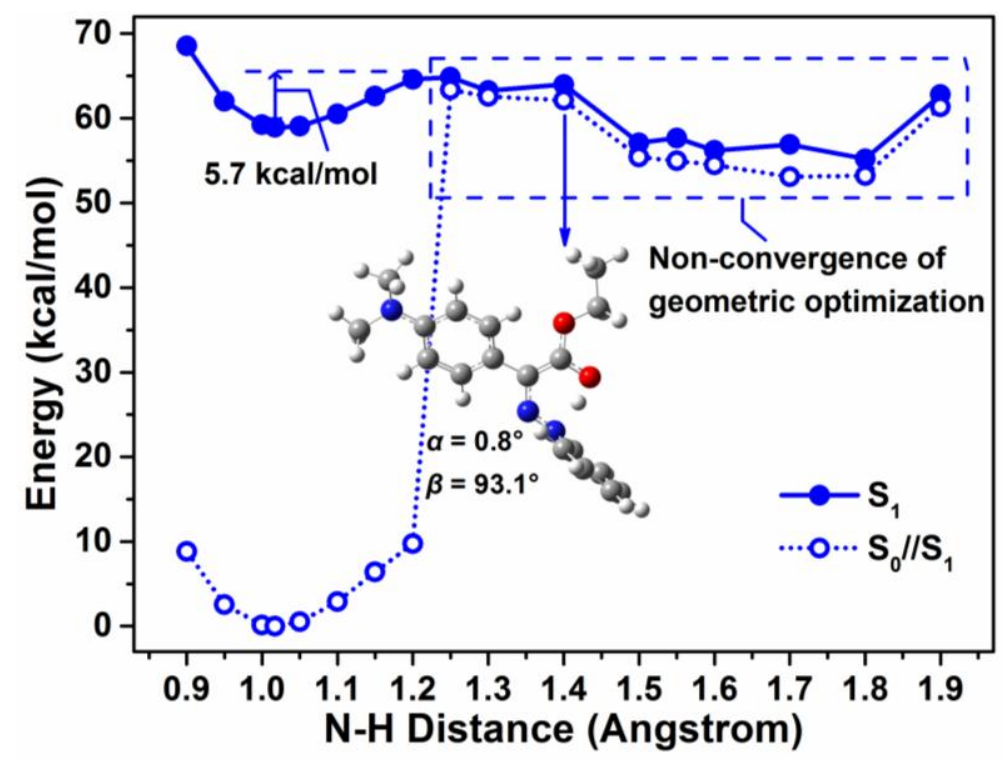

Figure S6. Calculated potential energy profiles of the $S_{0}$ and $S_{1}$ states of DMA-PHA in toluene along the N-H distance at TD-M06-2X/6-311+G(d,p) level, bond distances are given in angstroms; $\left(S_{1}\right.$ and $S_{0}$ : the potential energy profile of the $S_{1}$ and $S_{0}$ state; $S_{0} / / S_{1}$ : vertically projected $S_{0}$ energy on top of optimized $S_{1}$ geometries). The insets are the representative $S_{1}$ structures of DMA-PHA with the $\mathrm{N}-\mathrm{H}$ distance of 1.4 angstrom in the region of the $\mathrm{S}_{1} / \mathrm{S}_{0}$ degeneracy optimized by TD-M06-2X method in toluene.

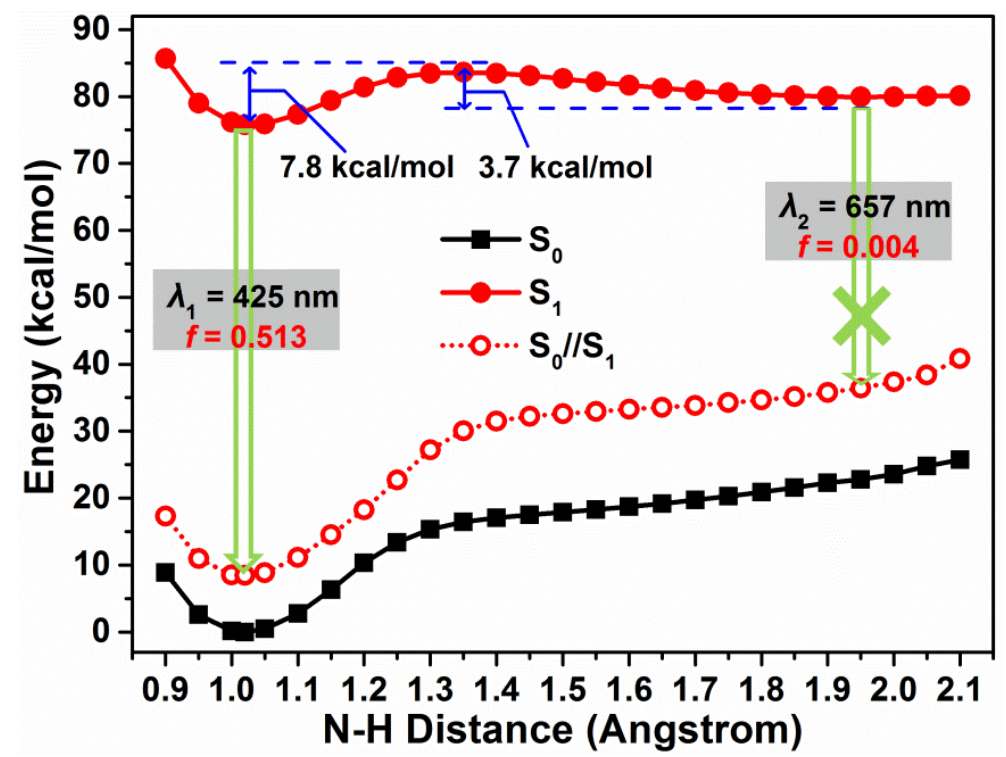

Figure S7. Calculated potential energy profiles of the $S_{0}$ and $S_{1}$ states of DMA-PHA in the crystal state along with the N-H distance using TD-M06-2X method, bond distances are given in angstroms; $\left(S_{1}\right.$ and $S_{0}$ : the potential energy profile of the $S_{1}$ and $S_{0}$ state; $S_{0} / / S_{1}$ : vertically projected $S_{0}$ energy on top of optimized $\mathrm{S}_{1}$ geometries). 
We failed to optimize the full $S_{1}$ PES in toluene due to the non-convergence of geometric optimization within the ranging of the $\mathrm{N}-\mathrm{H}$ bond length from 1.3 to 2.0 angstrom, where the $S_{0}$ and $S_{1}$ states are degenerate as shown in Figure $2 b$ and Figure S6. This is because there exists the rotation motion of the phenyl group connected the $\mathrm{N}$ atom end in the $\mathrm{S}_{1}$ state, a commonly-found fluoresence quenching channel in similar molecular system (J. Chem. Theory Comput. 2019, 15, 5440-5447; Chem. Lett. 2018, 47, 1083-1089). Based on this result, it can be reasonable to suggest that the ESIPT product is nonemissive due to the easy occurrence of the nonradiative $\mathrm{S}_{1} \rightarrow \mathrm{S}_{0}$ transition. Since the emission of DMA-PHA- $Z$ in the crystal state is immensely enhanced compared to that in toluene solution, and its emission mechanism is speculated as the same as that in toluene solution (reference 28), we calculated its $\mathrm{S}_{0}$ and $\mathrm{S}_{1}$ PES along with the $\mathrm{N}-\mathrm{H}$ distances in the crystal state. The results are shown in Figure S7. It can be observed that there is the presence of the large energy barrier of $7.8 \mathrm{kcal} / \mathrm{mol}$ at TD-M06-2X/6-31G(d,p) level for the ESIPT reaction, and the energy of ESIPT product is much bigger than the compound in its normal form. Thus, ESIPT from phenylamino proton to the carbonyl oxygen is kinetically and thermodynamically unfavorable for DMA-PHA-Z in accordance with that in toluene solution. Additionally, the ESIPT product of DMA-PHA is nonemissive because its corresponding $\mathrm{S}_{1} \rightarrow \mathrm{S}_{0}$ transition with the oscillator strength of 0.004 is nearly forbidden, which does not accord with the experimental result. Considering these above facts, the nature of fluorescence emission at around $525 \mathrm{~nm}$ (references 27 and 28) in toluene solution and the crystal state doesn't involve the ESIPT process. 


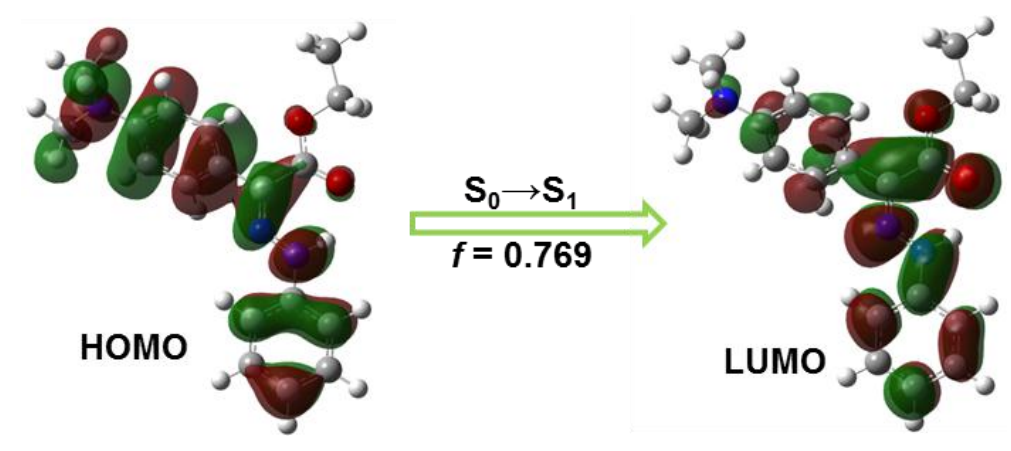

Figure S8. The oscillator strength $(f)$ and key orbitals (isovalue $=0.02$ ) of DMA-PHA- $Z$ in toluene involved in its corresponding $S_{0} \rightarrow S_{1}$ transition at FC point.
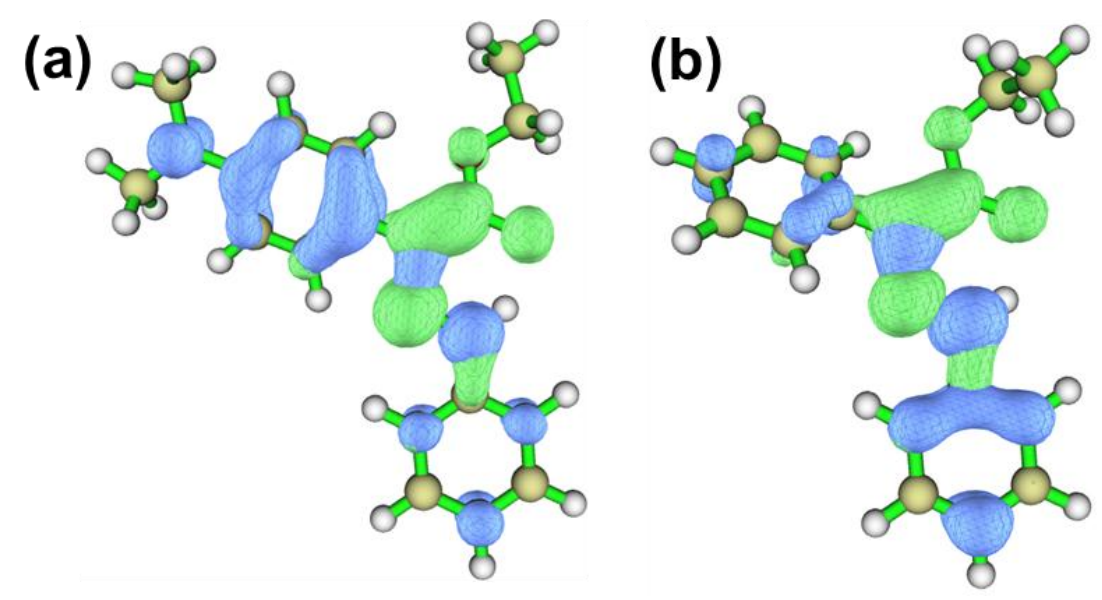

Figure S9. Electron-hole distributions for $\mathrm{S}_{1} \rightarrow \mathrm{S}_{0}$ transition of DMA-PHA- $Z$ in toluene at local minimum on $S_{1}$ state corresponding to the emissive state (a) and PHA- $Z$ in toluene at the Franck-Condon point on the $S_{1}$ state (b) (green = electron; blue $=$ hole). 

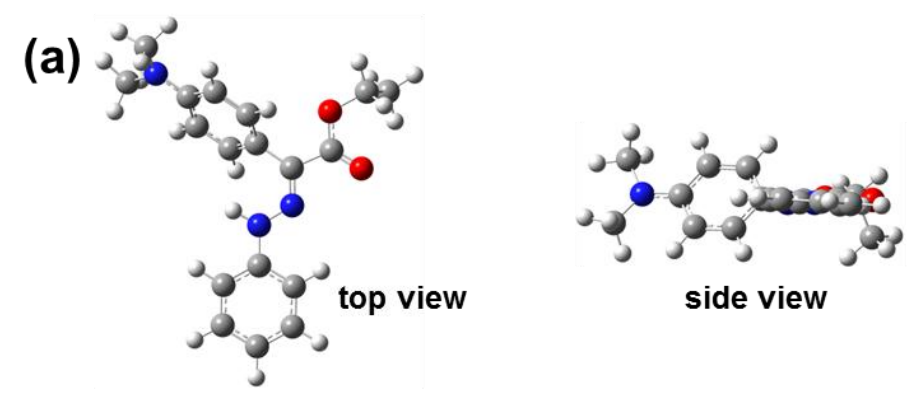

(b)

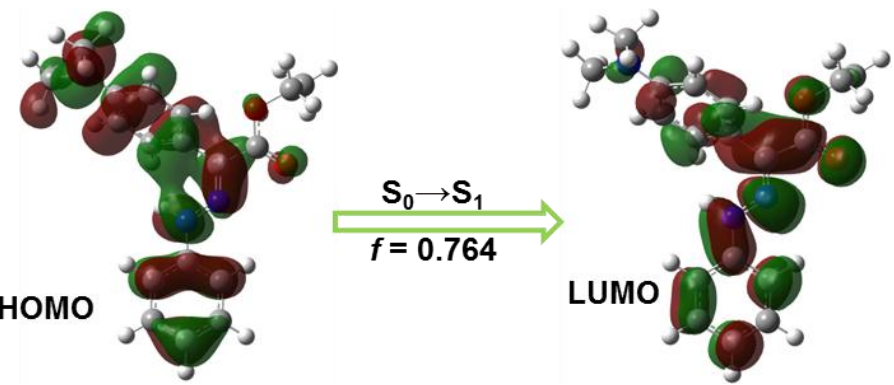

Figure S10. (a) Optimized geometrical structure of DMA-PHA-E in toluene at the $S_{0}$ minimum. (b) The oscillator strength $(f)$ and key orbitals (isovalue $=0.02$ ) of DMA-PHA- $E$ in toluene involved in its corresponding $\mathrm{S}_{0} \rightarrow \mathrm{S}_{1}$ transition at FC point.

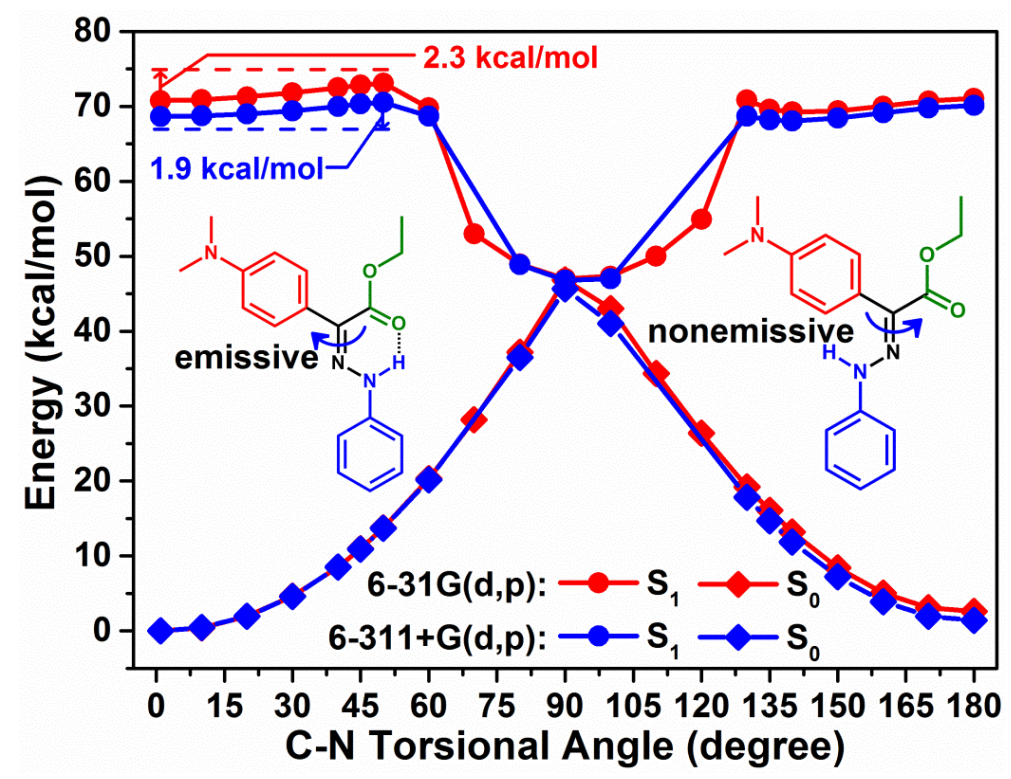

Figure S11. Potential energy surfaces of the $S_{0}$ (solid diamond line) and $S_{1}$ (solid circle line) states of DMA-PHA in toluene along with the isomerization coordinates at TD-M06-2X/6-31G(d,p) (red line) and TD-M06-2X/6-311+G(d,p) (blue line) levels. 


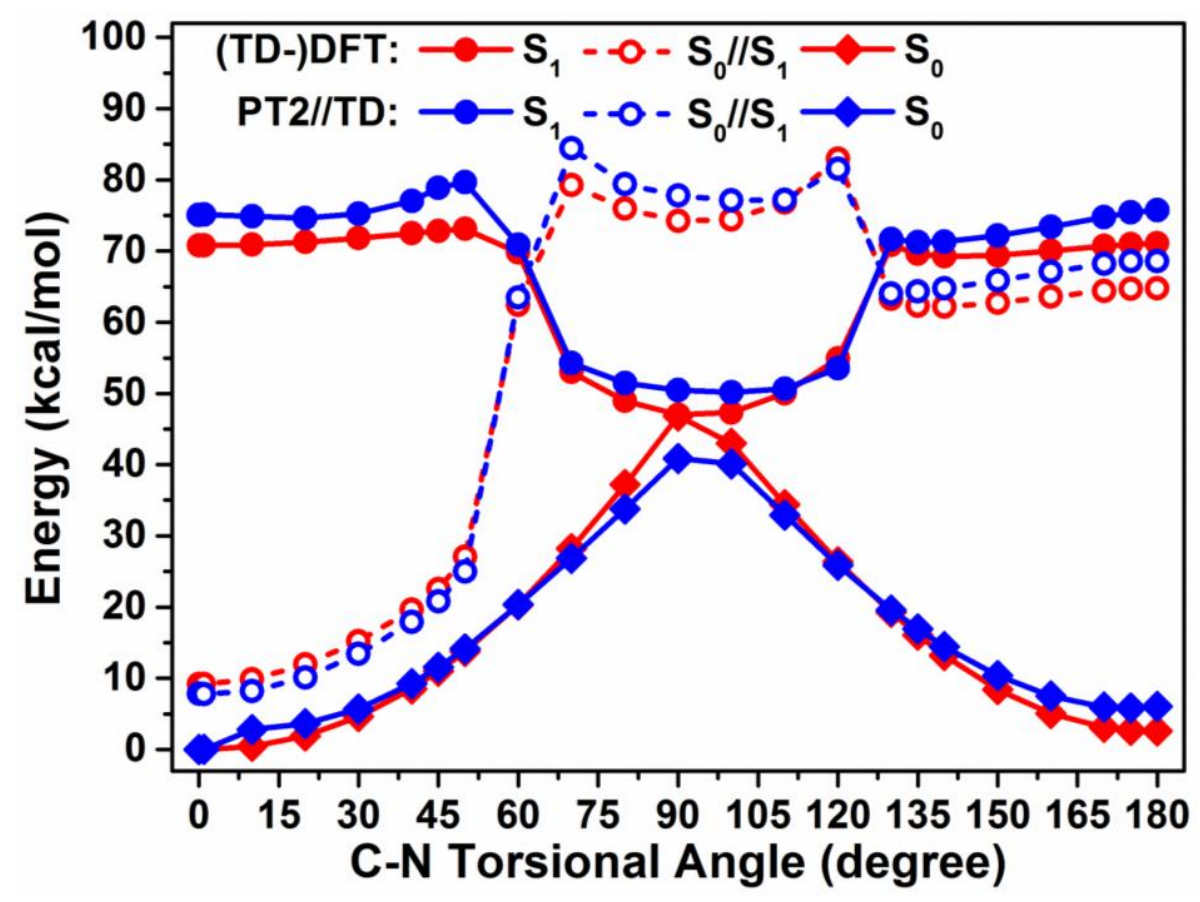

Figure S12. Calculated excited-state and ground-state energy profiles of DMA-PHA- $Z$ in toluene along the $\alpha$ dihedral angles corresponding to rotational motion about $\mathrm{C}=\mathrm{N}$ bond ((TD-)DFT (red line): energy profile computed by (TD-)M06-2X method; PT2//TD (blue line): MS-CASPT2 energy profile computed on the basis of (TD-)M06-2X optimized geometries; $S_{1}$ and $S_{0}$ : the potential energy profile of the $S_{1}$ and $S_{0}$ state; $S_{0} / / S_{1}$ : vertically projected $S_{0}$ energy on top of optimized $S_{1}$ geometries). 

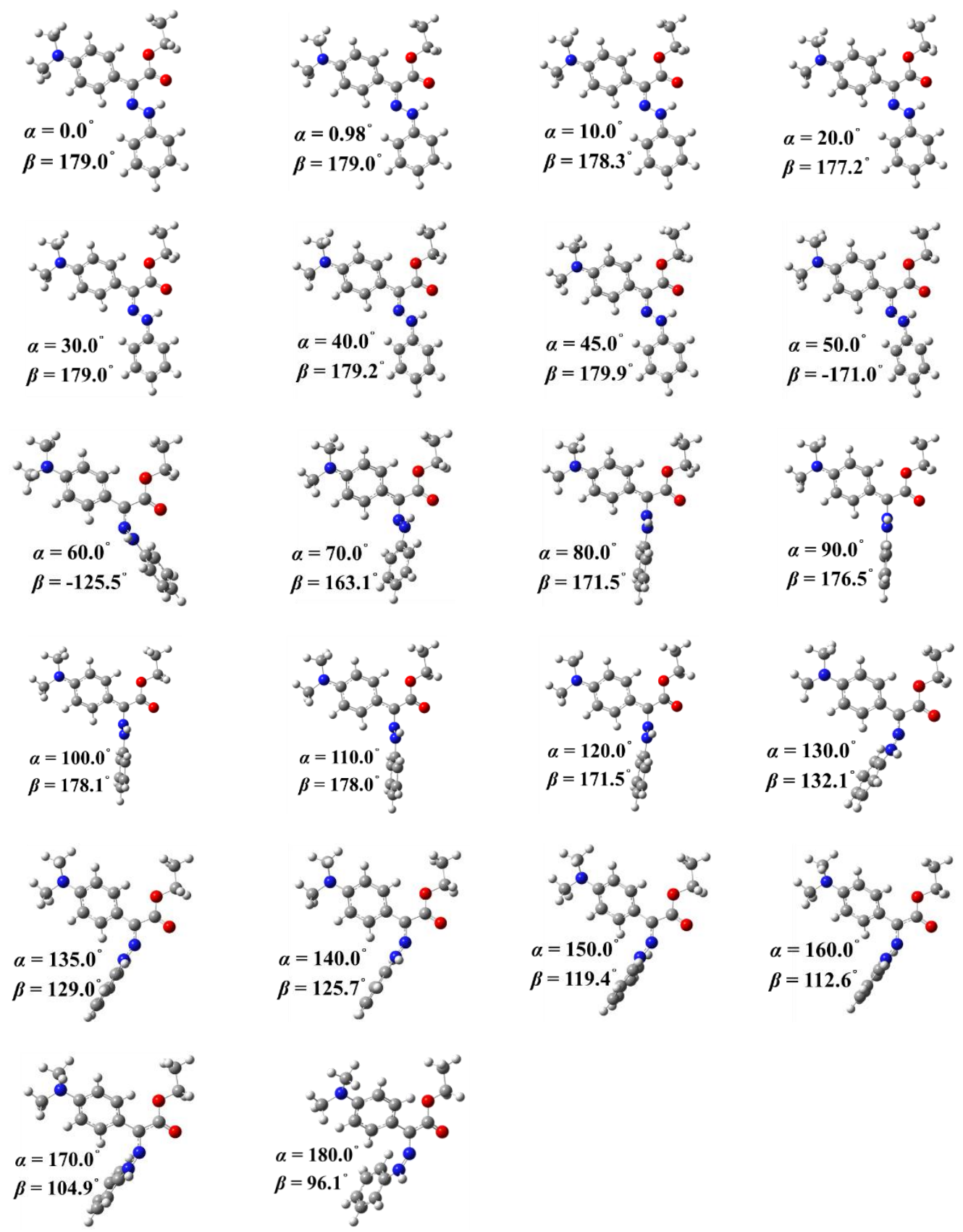

Figure S13. Optimized $\mathrm{S}_{1}$ geometrical structures of DMA-PHA with different $\alpha$ dihedral angles in toluene. The variations of $\alpha$ and $\beta$ dihedral angles corresponds to rotational motion about $\mathrm{C}=\mathrm{N}$ bond and $\mathrm{N}-\mathrm{N}$ bond, respectively. 


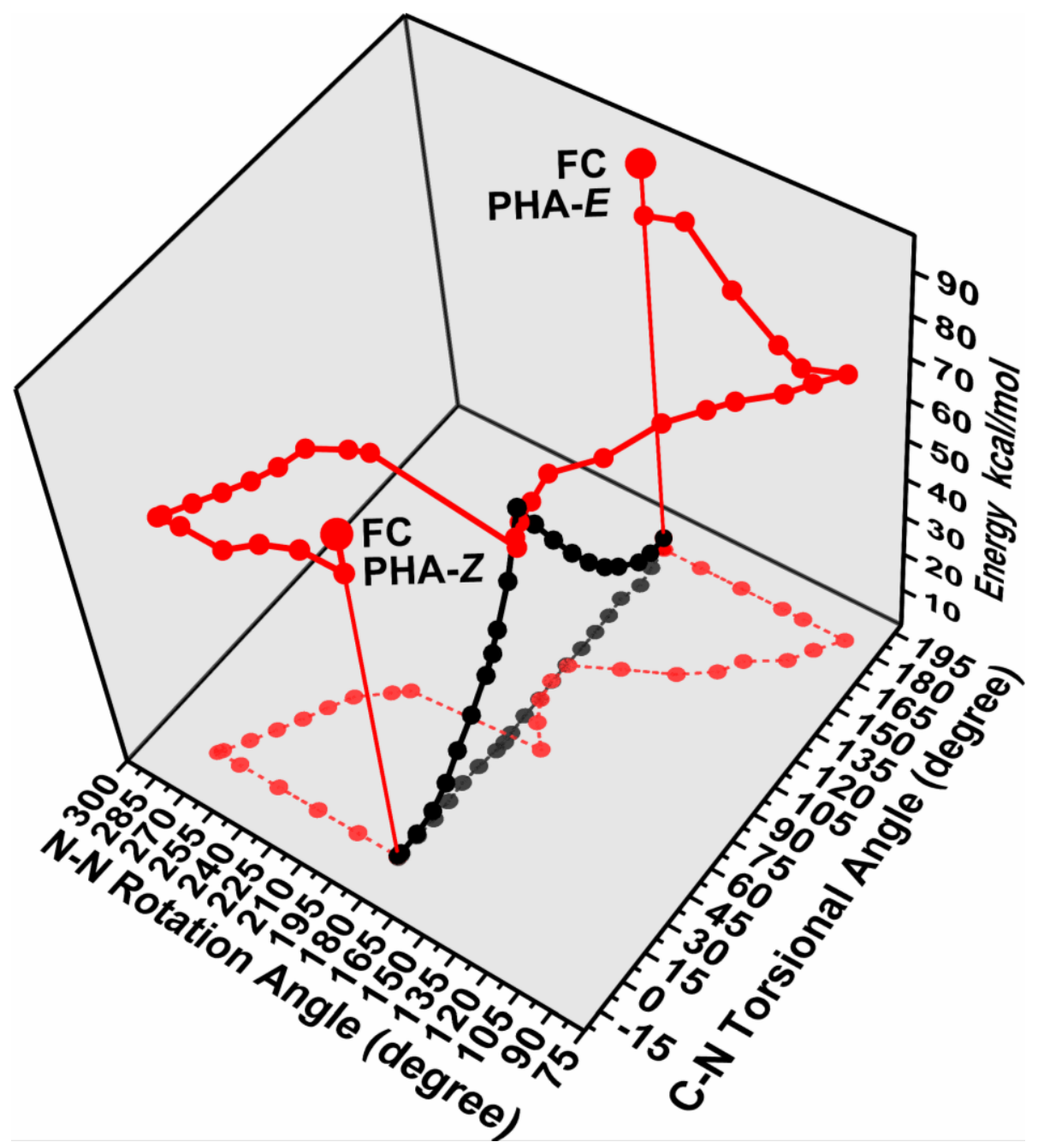

Figure S14. Potential energy surfaces of the $S_{0}$ (black solid circle line) and $S_{1}$ (red solid circle line) states of PHA in toluene computed by TD-M06-2X method at different dihedral angles with respect to $\mathrm{C}=\mathrm{N}$ bond torsion coordinate illustrating the photoisomerization mechanism; Dotted black and red lines represent geometry variations along the $\alpha^{\prime}$ dihedral angles (XY plane). 

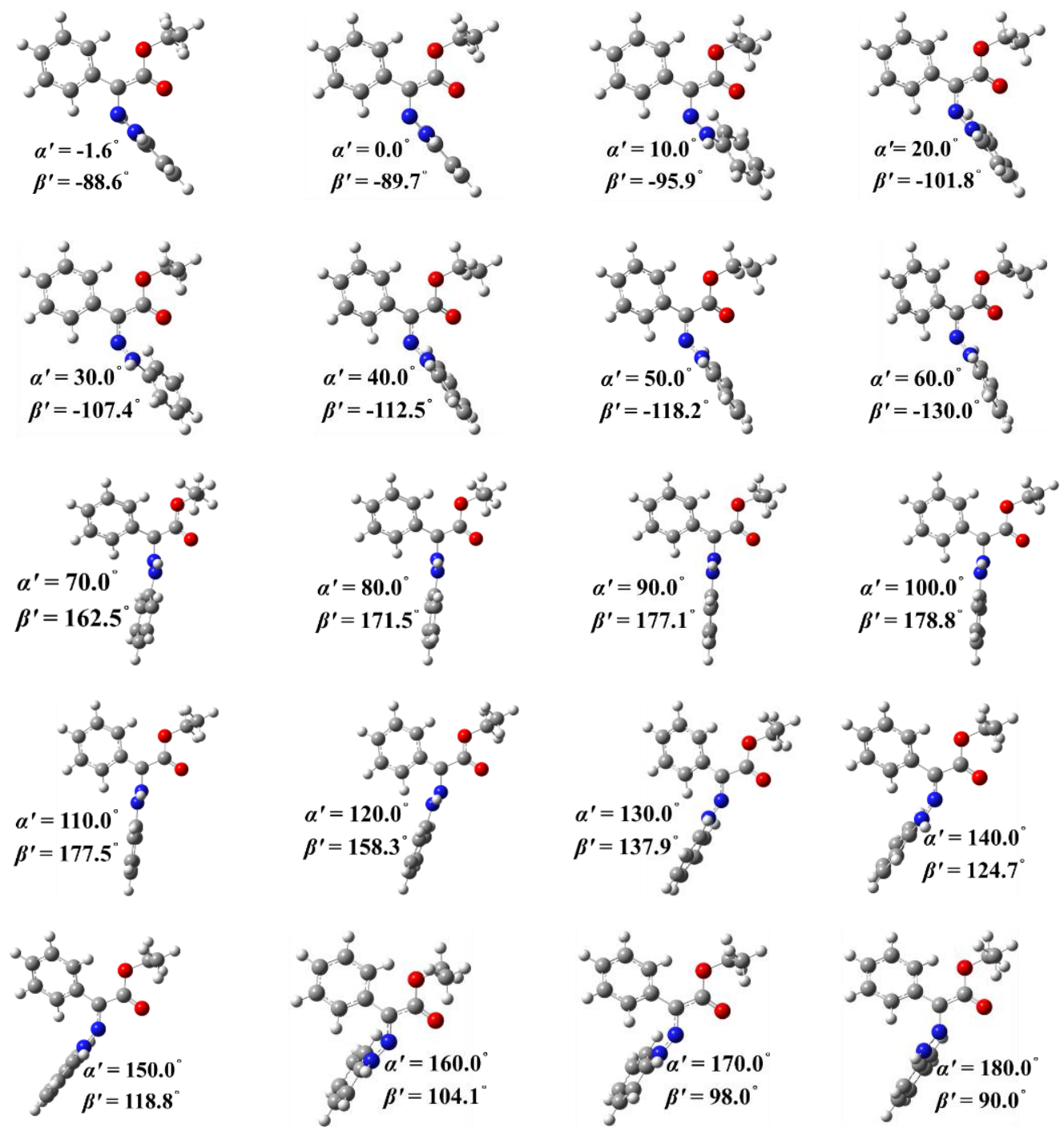

Figure S15. Optimized $\mathrm{S}_{1}$ geometrical structures of PHA with different $\alpha^{\prime}$ dihedral angles in toluene. The variations of $\alpha^{\prime}$ and $\beta^{\prime}$ dihedral angles corresponds to rotational motion about $\mathrm{C}=\mathrm{N}$ bond and $\mathrm{N}-\mathrm{N}$ bond, respectively. 


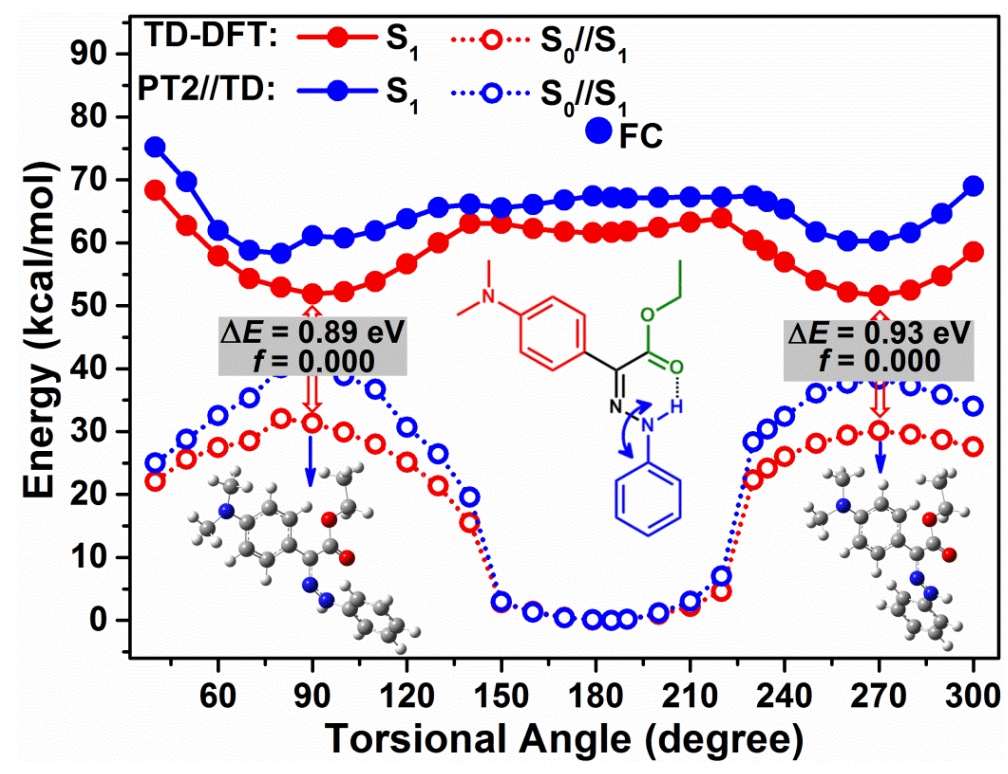

Figure S16. Calculated excited-state and ground-state energy profiles of DMA-PHA- $Z$ in toluene along the $\beta$ dihedral angles with fixing the $\alpha$ dihedral angle to be $1.0^{\circ}$ (TD-DFT (red line): energy profile computed by TD-M06-2X method; PT2//TD (blue line): MS-CASPT2 energy profile computed on the basis of TD-M06-2X optimized geometries; $S_{1}$ : the potential energy surface of the $S_{1}$ state; $S_{0} / / S_{1}$ : vertically projected $S_{0}$ energy on top of optimized $S_{1}$ geometries).

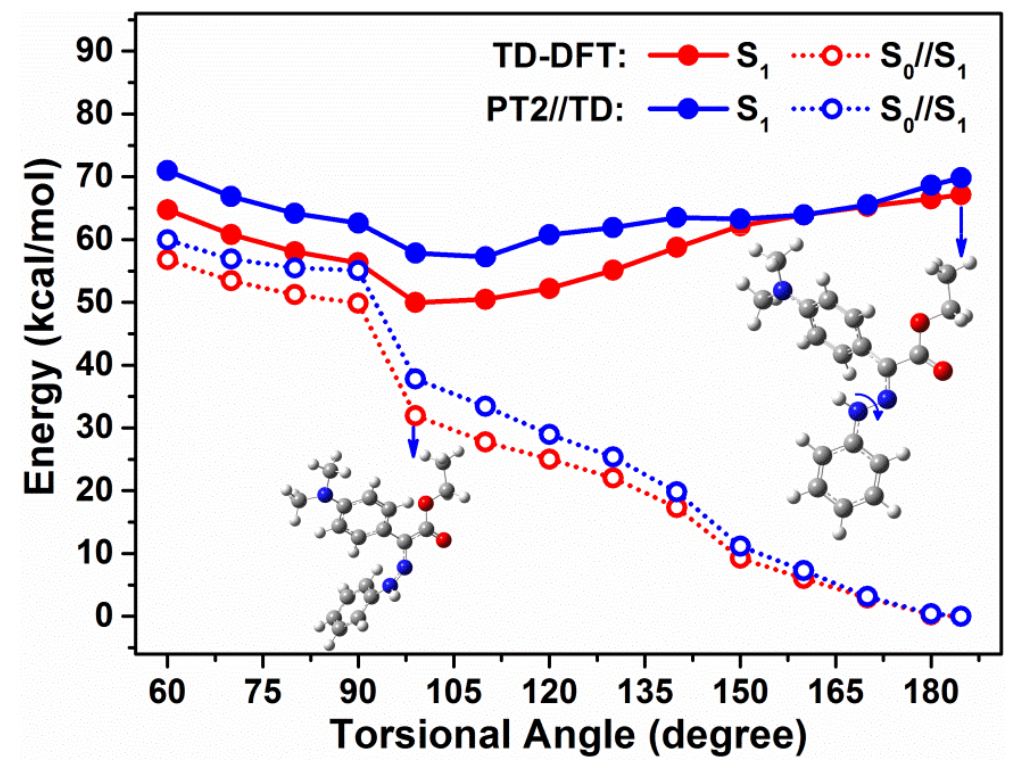

Figure S17. Calculated excited-state and ground-state energy profiles of DMA-PHA- $E$ in toluene along the $\beta$ dihedral angles with fixing the $\alpha$ dihedral angle to be $178.0^{\circ}$ (TD-DFT (red line): energy profile computed by TD-M06-2X method; PT2//TD (blue line): MS-CASPT2 energy profile computed on the basis of TD-M06-2X optimized geometries; $S_{1}$ : the potential energy surface of the $S_{1}$ state; $S_{0} / / S_{1}$ : vertically projected $S_{0}$ energy on top of optimized $S_{1}$ geometries). 


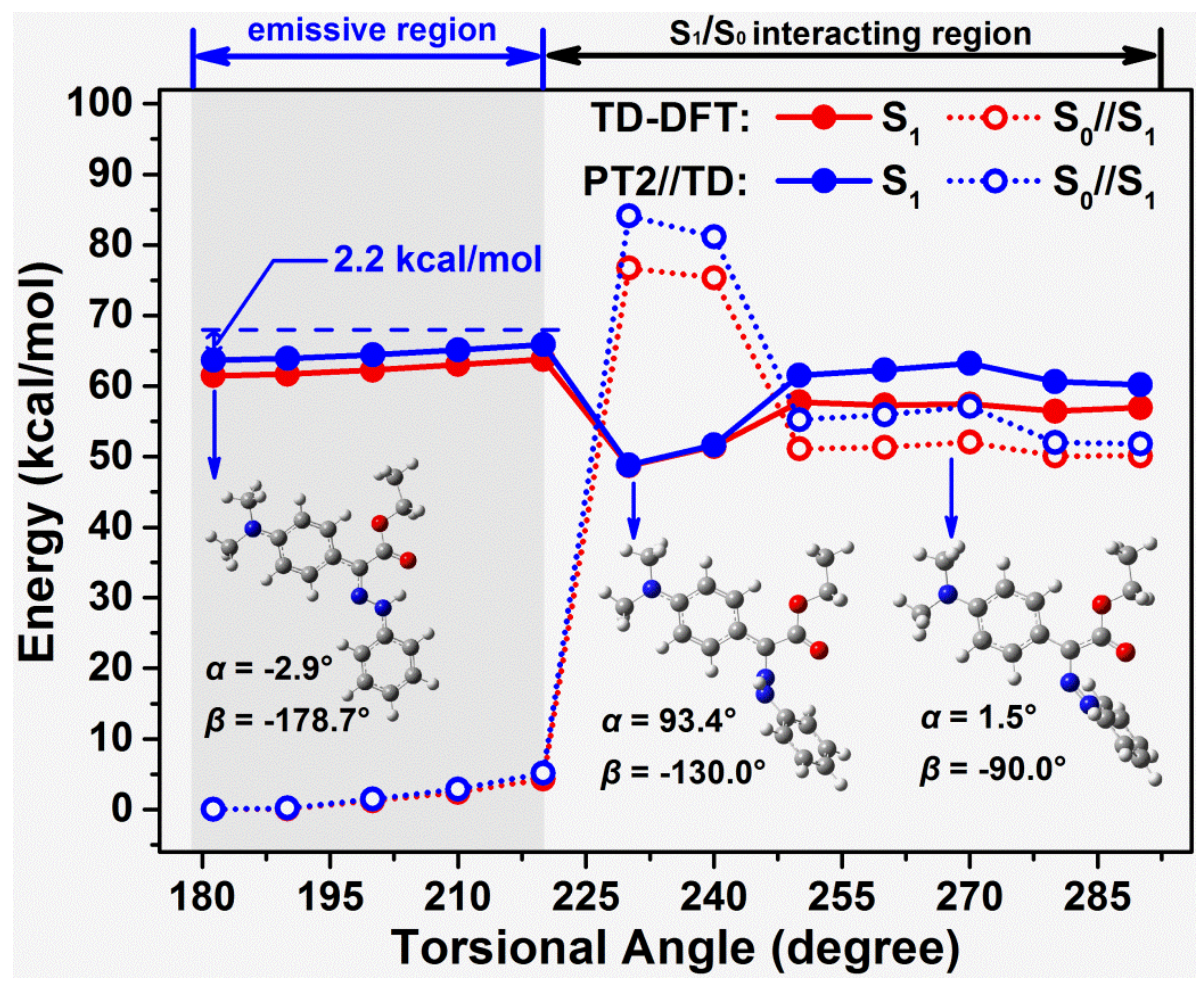

Figure S18. Calculated excited-state and ground-state energy profiles of DMA-PHA- $Z$ in toluene along the $\beta$ dihedral angles corresponding to rotational motion about $\mathrm{N}-\mathrm{N}$ bond (TD-DFT (red line): energy profile computed by TD-M06-2X method; PT2//TD (blue line): MS-CASPT2 energy profile computed on the basis of TD-M06-2X optimized geometries; $S_{1}$ : the potential energy surface of the $S_{1}$ state; $S_{0} / / S_{1}$ : vertically projected $S_{0}$ energy on top of optimized $S_{1}$ geometries). The insets are selected $S_{1}$ structures of DMA-PHA with different $\beta$ dihedral angles in toluene optimized by TD-M06-2X method. 

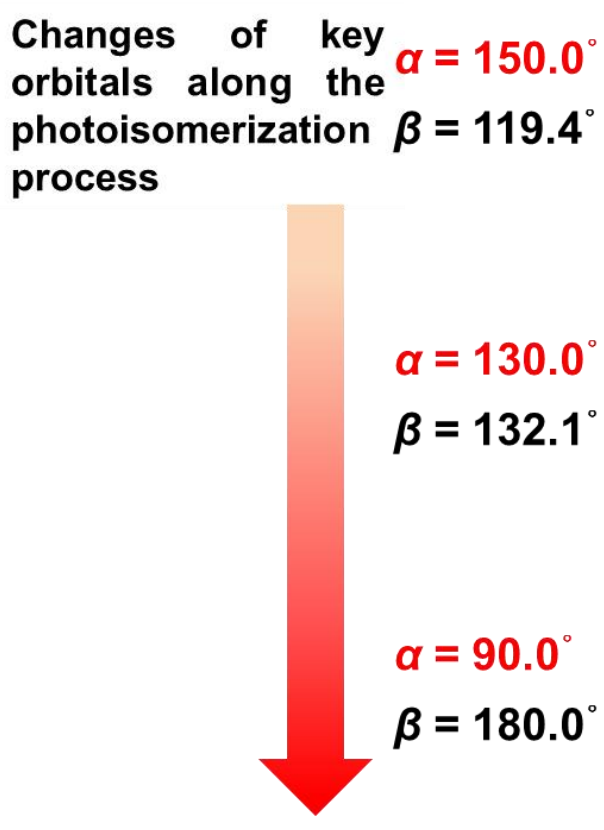
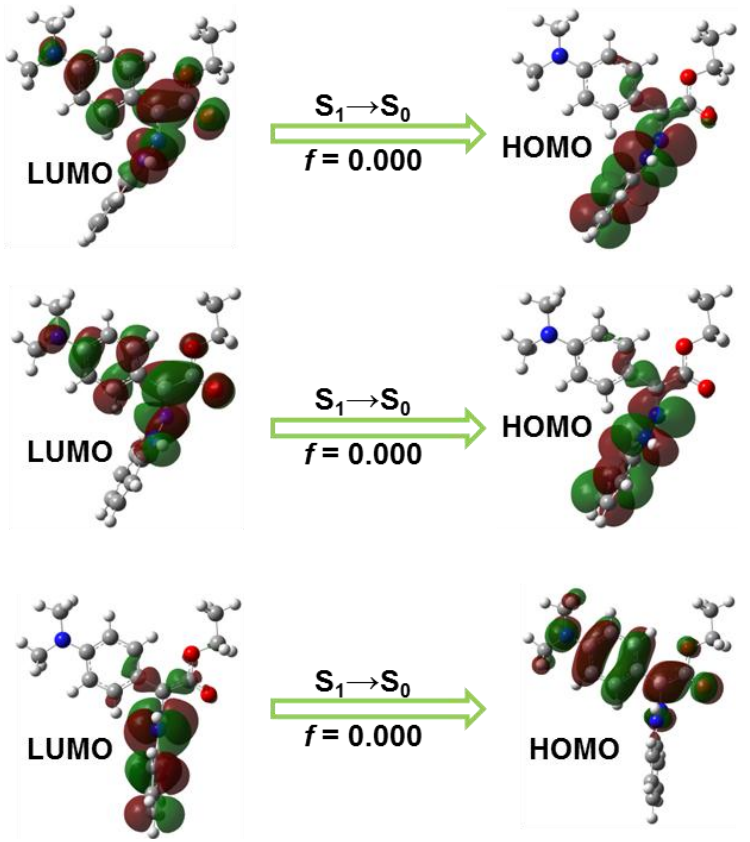

Figure S19. The oscillator strength $(f)$ and key orbitals (isovalue $=0.02$ ) of DMA-PHA- $E$ in toluene involved in its corresponding $S_{1} \rightarrow S_{0}$ transition along the minimum energy path based on $\mathrm{S}_{1}$ optimized geometrical structures with different fixed $\alpha$ and $\beta$ dihedral angles. The variations of $\alpha$ and $\beta$ dihedral angles correspond to rotational motion about $\mathrm{C}=\mathrm{N}$ bond and $\mathrm{N}-\mathrm{N}$ bond, respectively. 

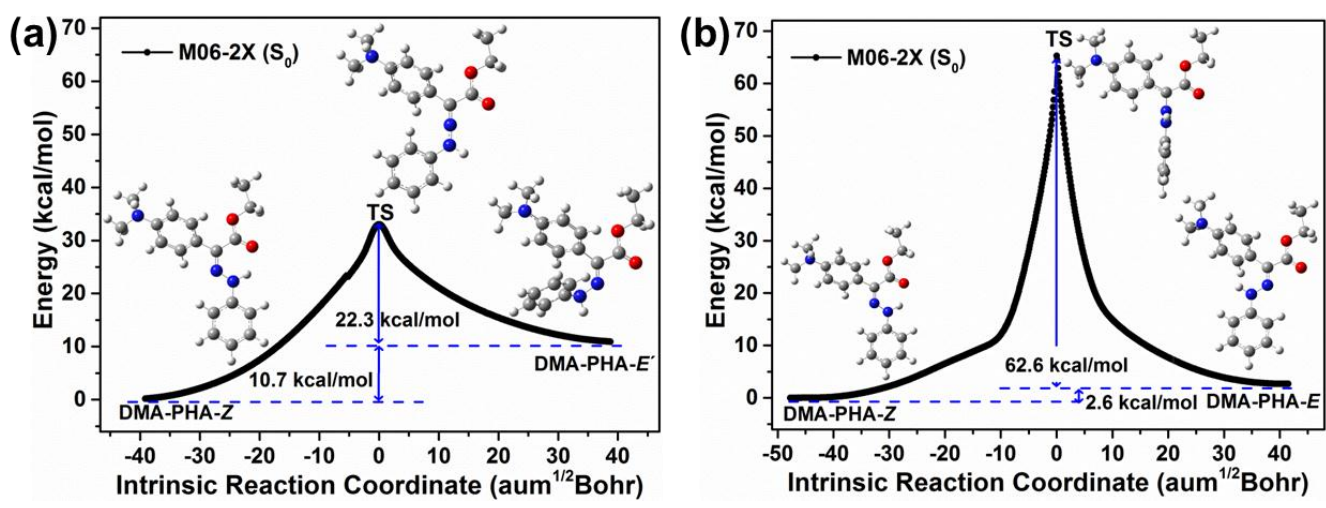

Figure S20. Energy profile along the intrinsic reaction coordinates for thermal isomerization of DMA-PHA from $Z$ configuration to $E$ configuration through in-plane nitrogen inversion (a) and out-of-plane rotation about the $\mathrm{C}=\mathrm{N}$ bond (b). The energy barriers for the inversion and rotation mechanisms are $33.0 \mathrm{kcal} / \mathrm{mol}$ (a) and $65.2 \mathrm{kcal} / \mathrm{mol}(\mathrm{b})$, respectively.

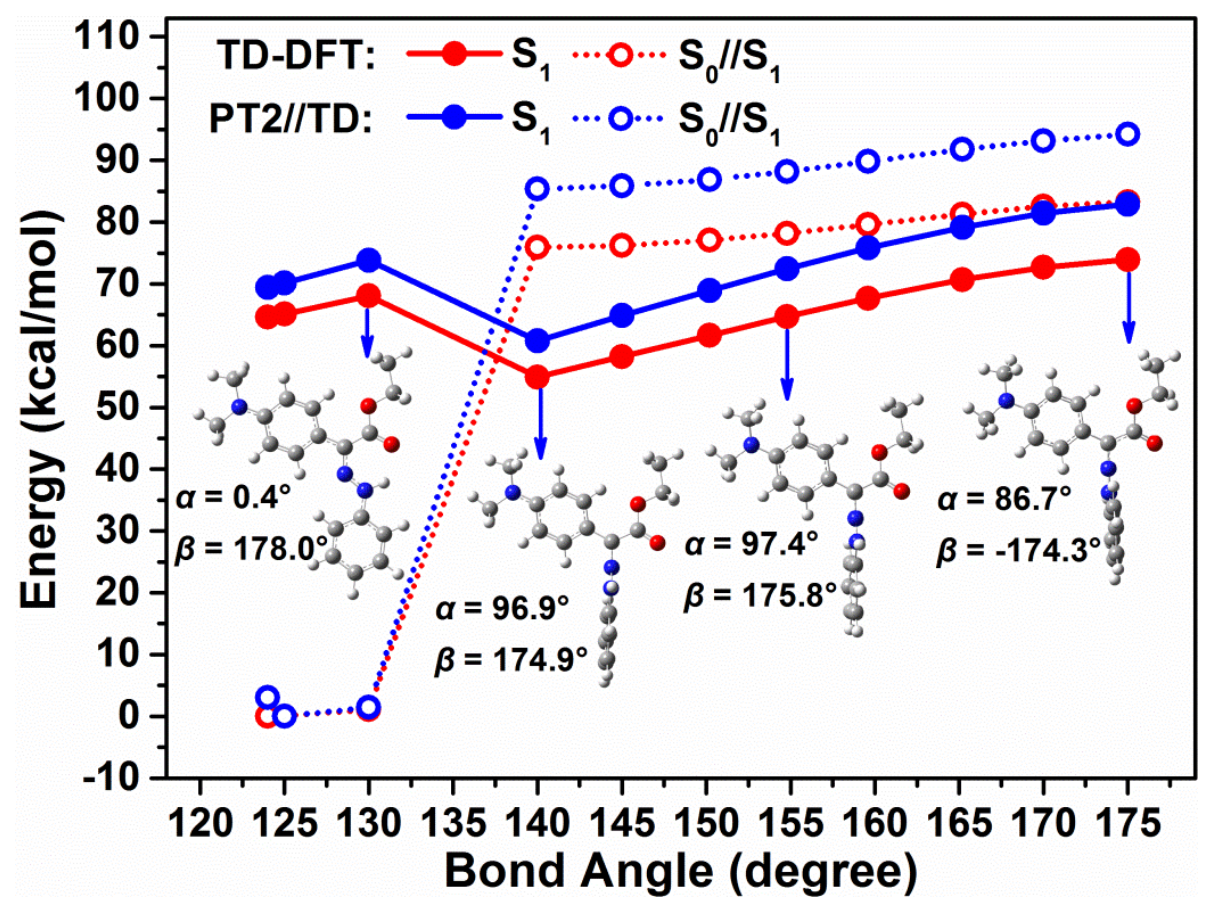

Figure S21. Calculated excited-state and ground-state energy profiles of DMA-PHA- $Z$ in toluene along the $\mathrm{C}=\mathrm{N}-\mathrm{N}$ bond angles involved in in-plane nitrogen inversion mechanism (TD-DFT (red line): energy profile computed by TD-M06-2X method; PT2//TD (blue line): MS-CASPT2 energy profile computed on the basis of TD-M06-2X optimized geometries; $S_{1}$ : the potential energy surface of the $S_{1}$ state; $S_{0} / / S_{1}$ : vertically projected $S_{0}$ energy on top of optimized $S_{1}$ geometries). The insets are selected $S_{1}$ structures of DMA-PHA with different $\beta$ dihedral angles in toluene optimized by TD-M06-2X method. 

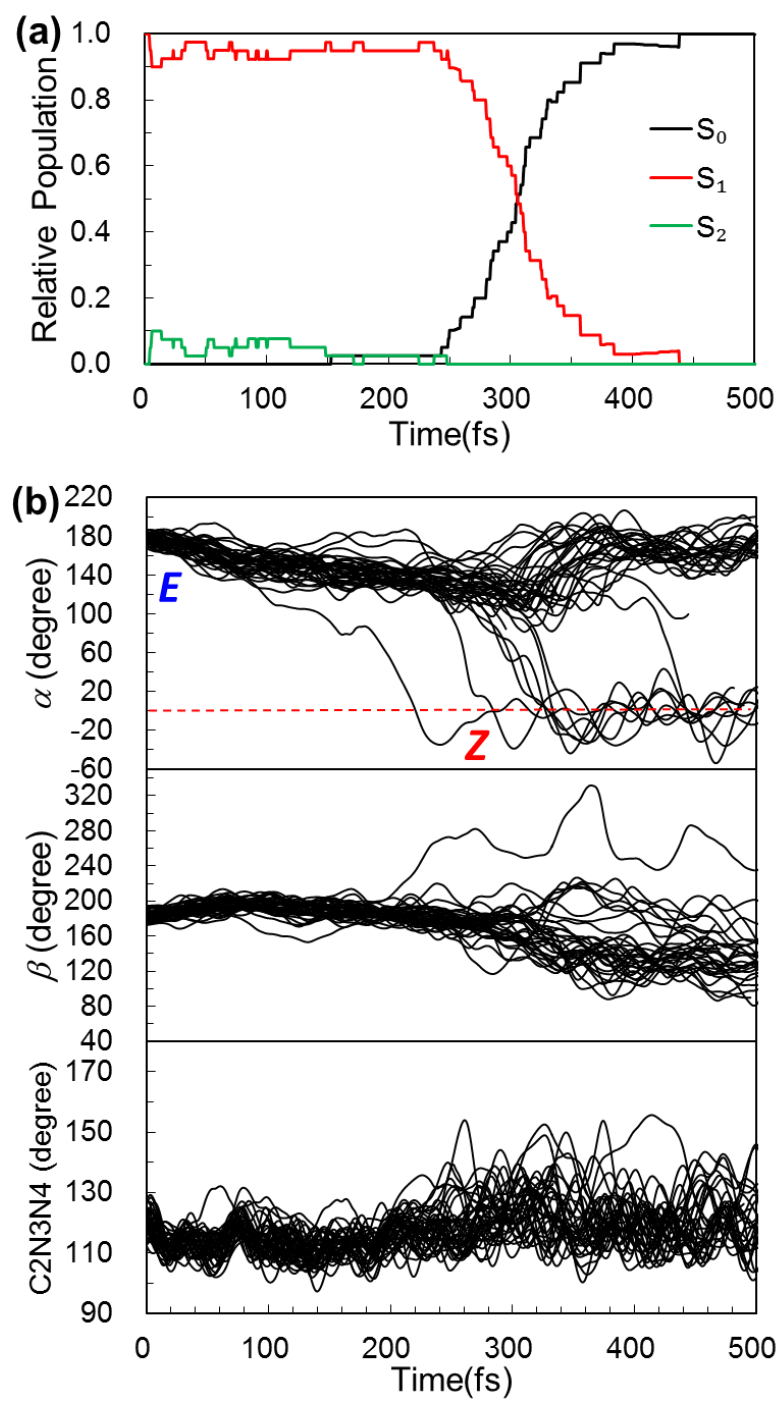

Figure S22. (a) State populations for an ensemble of 37 trajectories. (b) Evolution of the $\alpha$ and $\beta$ dihedral angles and the C2N3N4 bond angle along each nonadiabatic trajectory of DMA-PHA-E. 


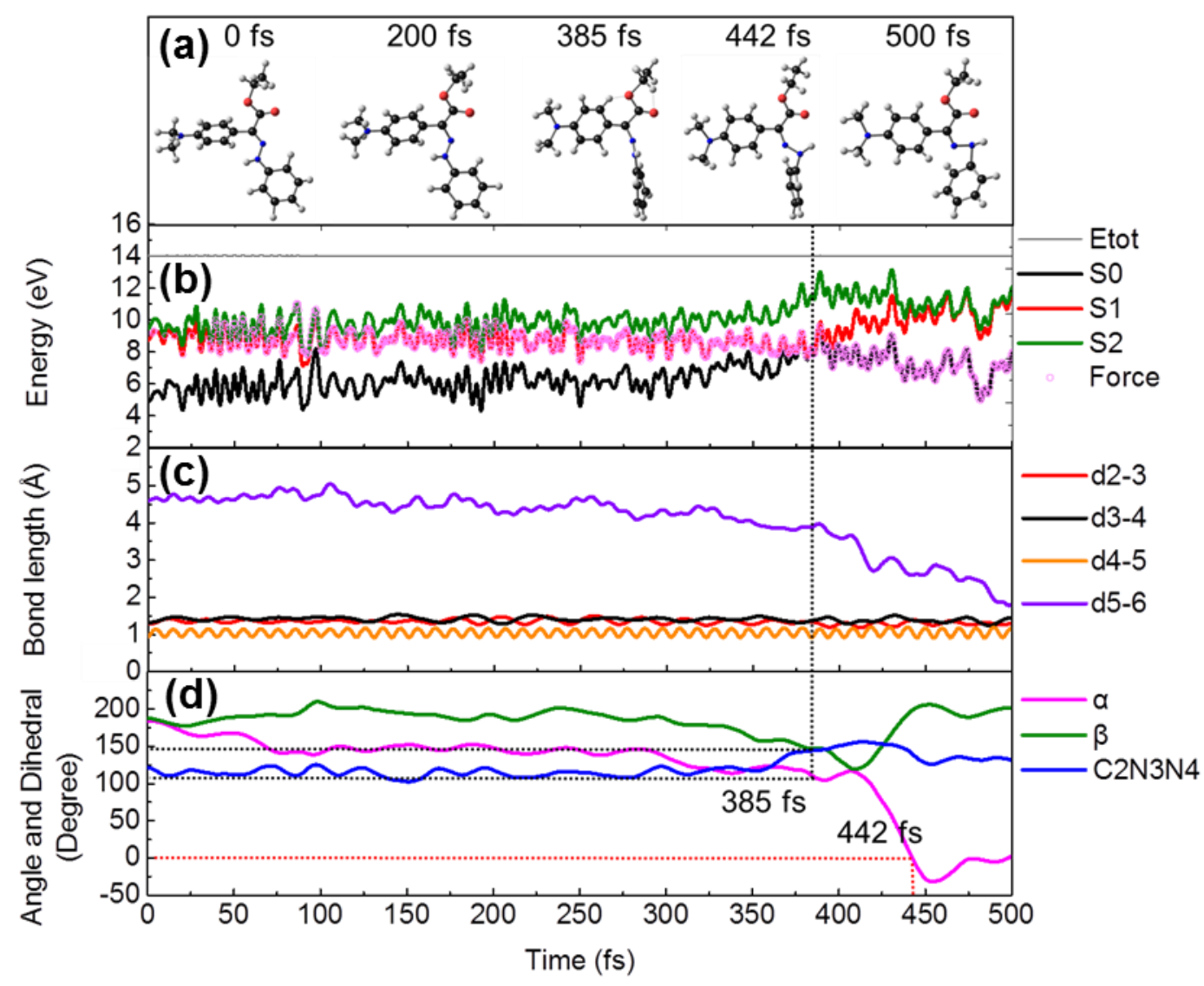

Figure S23. The representative nonadiabatic trajectory of DMA-PHA-E in TSH molecular dynamics. (a) Structures of the representative trajectory at 0, 200, 385, 442 and 500 fs. (b) Total and potential energies of three states in the simulation, the tracking state (force state) is emphasized in pink circle. (c) Evolution of the C2-N3 (red), N3-N4 (black), N4-H5 (yellow) and H5-O6 (purple) distances along the representative trajectory. (d) Evolution of the $\alpha$ (pink) and $\beta$ (green) dihedral angles and the $\mathrm{C} 2 \mathrm{~N} 3 \mathrm{~N} 4$ bond angle (blue) along the representative trajectory. 
Figure S22a shows state populations starting from the FC point of DMA-PHA-E. It can be found that the average time for the $S_{1}$-to- $S_{0}$ population transfer is $306 \mathrm{fs}$. Finally, all the trajectories stay on the ground state. Geometric analyses on 37 trajectories that successfully hop from $S_{1}$ to $S_{0}$ state demonstrate that the $\alpha$ dihedral angle gradually varies from $180.0^{\circ}$ to $90.0^{\circ}$ accompanying the changes of the $\beta$ dihedral angle (its average value of the maximum deviation in each trajectory relative to that of the initial geometries is $28.1^{\circ}$ ) during the structural relaxation process before the average time (Figure S22b). Meanwhile, the C2N3N4 band angle fluctuates subtly around $120.0^{\circ}$, but it does not proceed through $180.0^{\circ}$ (a linear transition state for a planar inversion mechanism).

As shown in Figure $\mathrm{S} 23 \mathrm{~b}$, the time for $\mathrm{S}_{1}$-to- $\mathrm{S}_{0}$ hopping of the representative trajectory of DMA-PHA- $E$ is 385 fs. During this time range, $\alpha$ and $\beta$ dihedral angles vary simultaneously. Moreover, the key geometric parameters of the representative trajectory of DMA-PHA-E present the observed variation (Figures S23c, S23d). At $442 \mathrm{fs}$, the great changes of the H5-O6 distance (from $4.601 \AA$ to $2.594 \AA$ ) and the $\alpha$ dihedral angle (from $180.0^{\circ}$ to $0.0^{\circ}$ ) indicate that the $E \rightarrow Z$ isomerization is finished.

Considering comprehensively the above results from the TSH dynamic simulations, we can conclude that $\mathrm{C}=\mathrm{N}$ bond and $\mathrm{N}-\mathrm{N}$ bond rotation motion are the inseparable and essential factors for photoisomerization process of DMA-PHA, and the planar inversion mechanism in excited state is impossible, which is consistent with that from the TD-DFT calculation. 


\section{Part II. Cartesian coordinates}

Cartesian coordinates of important geometries of DMA-PHA and PHA optimized at (TD)-M06-2X/6-31G(d,p) level of theory

$S_{0}$-min- $Z$ (the $S_{0}$ minimum of DMA-PHA-Z)

Energy: -1012.84145226

$\begin{array}{llllllll}\mathrm{O} & -0.663970 & 2.835720 & -0.165550 & \mathrm{C} & 4.977449 & -0.037407 & 0.074005 \\ \mathrm{O} & 1.553031 & 2.770068 & 0.127308 & \mathrm{H} & 2.790545 & 1.357055 & 0.101966 \\ \mathrm{~N} & 1.370290 & -0.081178 & 0.087562 & \mathrm{H} & -0.288064 & -1.568915 & -1.190311 \\ \mathrm{~N} & 2.613011 & 0.355543 & 0.085544 & \mathrm{H} & -2.410554 & -2.766314 & -1.249184 \\ \mathrm{~N} & -4.707208 & -1.977146 & -0.094603 & \mathrm{H} & -4.159839 & 0.300194 & 1.232325 \\ \mathrm{C} & 0.484350 & 2.186302 & 0.026890 & \mathrm{H} & -2.038027 & 1.465588 & 1.269988 \\ \mathrm{C} & 0.335846 & 0.706849 & 0.071292 & \mathrm{H} & -4.429303 & -3.373946 & -1.643594 \\ \mathrm{C} & -0.993493 & 0.050111 & 0.026078 & \mathrm{H} & -5.767650 & -3.706746 & -0.545930 \\ \mathrm{C} & -1.144724 & -1.156611 & -0.665688 & \mathrm{H} & -4.097855 & -4.016699 & -0.020799 \\ \mathrm{C} & -2.351883 & -1.836548 & -0.697218 & \mathrm{H} & -5.485777 & -1.636668 & 1.859922 \\ \mathrm{C} & -3.487362 & -1.326748 & -0.034752 & \mathrm{H} & -6.647495 & -2.168654 & 0.623230 \\ \mathrm{C} & -3.329922 & -0.122068 & 0.679698 & \mathrm{H} & -6.044769 & -0.512671 & 0.602585 \\ \mathrm{C} & -2.113741 & 0.544525 & 0.702685 & \mathrm{H} & 0.079815 & 4.532828 & -1.080986 \\ \mathrm{C} & -4.743532 & -3.337160 & -0.595951 & \mathrm{H} & -0.106598 & 4.641756 & 0.674007 \\ \mathrm{C} & -5.765962 & -1.552381 & 0.799571 & \mathrm{H} & -1.960673 & 5.882731 & -0.496428 \\ \mathrm{C} & -0.571639 & 4.269366 & -0.243008 & \mathrm{H} & -2.607083 & 4.509172 & 0.421164 \\ \mathrm{C} & -1.978272 & 4.792956 & -0.425755 & \mathrm{H} & -2.421432 & 4.391509 & -1.339525 \\ \mathrm{C} & 3.676291 & -0.550780 & 0.076924 & \mathrm{H} & 2.457385 & -2.318799 & 0.073364 \\ \mathrm{C} & 3.469776 & -1.934004 & 0.068865 & \mathrm{H} & 4.402123 & -3.859151 & 0.051669 \\ \mathrm{C} & 4.567782 & -2.786340 & 0.057525 & \mathrm{H} & 6.717298 & -2.957385 & 0.045285 \\ \mathrm{C} & 5.867805 & -2.283413 & 0.054147 & \mathrm{H} & 7.068835 & -0.495416 & 0.060135 \\ \mathrm{C} & 6.063356 & -0.904024 & 0.062693 & \mathrm{H} & 5.131222 & 1.037950 & 0.079529\end{array}$


$S_{0}$-min- $E$ (the $S_{0}$ minimum of DMA-PHA-E)

\section{Energy: -1012.83732027}

$\begin{array}{llllllll}\mathrm{O} & 1.067650 & 2.979363 & -0.181080 & \mathrm{C} & -4.251197 & -0.116050 & -0.033482 \\ \mathrm{O} & -1.146780 & 3.377386 & -0.213304 & \mathrm{H} & 0.311860 & -0.745543 & 1.816437 \\ \mathrm{~N} & -1.579305 & 0.713428 & -0.017103 & \mathrm{H} & 2.243029 & -2.223597 & 1.864527 \\ \mathrm{~N} & -1.857754 & -0.579816 & 0.027594 & \mathrm{H} & 3.630511 & -0.482750 & -1.837536 \\ \mathrm{~N} & 4.228549 & -2.286528 & 0.056374 & \mathrm{H} & 1.687309 & 0.982001 & -1.858404 \\ \mathrm{C} & -0.351080 & 1.112453 & -0.060950 & \mathrm{H} & 0.603164 & 4.813472 & -1.012411 \\ \mathrm{C} & -0.221519 & 2.600813 & -0.156132 & \mathrm{H} & 2.320409 & 4.472037 & -0.678562 \\ \mathrm{C} & 0.841077 & 0.228294 & -0.031514 & \mathrm{H} & 1.854742 & 4.619609 & 1.784729 \\ \mathrm{C} & 1.035119 & -0.691386 & 1.005905 & \mathrm{H} & 0.148184 & 4.978661 & 1.430908 \\ \mathrm{C} & 2.139793 & -1.530935 & 1.038925 & \mathrm{H} & 1.414165 & 6.132229 & 0.969341 \\ \mathrm{C} & 3.116897 & -1.477661 & 0.022541 & \mathrm{H} & 4.613796 & -2.616481 & -2.005373 \\ \mathrm{C} & 2.914657 & -0.554941 & -1.028375 & \mathrm{H} & 5.927698 & -3.023262 & -0.884763 \\ \mathrm{C} & 1.806574 & 0.274790 & -1.043444 & \mathrm{H} & 5.579588 & -1.330999 & -1.249736 \\ \mathrm{C} & 1.304388 & 4.392465 & -0.288471 & \mathrm{H} & 4.329767 & -2.873061 & 2.077430 \\ \mathrm{C} & 1.171173 & 5.070588 & 1.061698 & \mathrm{H} & 5.276923 & -3.843396 & 0.946497 \\ \mathrm{C} & 5.124996 & -2.313556 & -1.081410 & \mathrm{H} & 3.514185 & -4.041706 & 1.016742 \\ \mathrm{C} & 4.334199 & -3.312442 & 1.073717 & \mathrm{H} & -2.596986 & -3.092997 & -0.045140 \\ \mathrm{C} & -3.183662 & -1.019460 & -0.023040 & \mathrm{H} & -4.918507 & -3.933347 & -0.119858 \\ \mathrm{C} & -3.430063 & -2.395603 & -0.053354 & \mathrm{H} & -6.828158 & -2.339765 & -0.139141 \\ \mathrm{C} & -4.738197 & -2.863373 & -0.095070 & \mathrm{H} & -6.377714 & 0.103068 & -0.084627 \\ \mathrm{C} & -5.808456 & -1.972148 & -0.106005 & \mathrm{H} & -4.045422 & 0.946991 & -0.012202 \\ \mathrm{C} & -5.552535 & -0.602173 & -0.074877 & \mathrm{H} & -1.108920 & -1.262799 & -0.051820\end{array}$


TS-I (Transition state for thermal isomerization of DMA-PHA from $Z$ configuration to $E$ configuration through in-plane nitrogen inversion)

\section{Energy: -1012.78886633}

$\begin{array}{llllllll}\mathrm{O} & -2.070404 & -2.677730 & 0.111145 & \mathrm{C} & 4.755178 & -0.741491 & 0.208751 \\ \mathrm{O} & -0.214237 & -3.918747 & -0.113820 & \mathrm{H} & 2.985789 & -2.601034 & 0.031585 \\ \mathrm{~N} & 1.273532 & -1.634119 & -0.017104 & \mathrm{H} & 0.645159 & 0.615805 & 1.463302 \\ \mathrm{~N} & 2.543532 & -1.684785 & 0.005621 & \mathrm{H} & -0.417576 & 2.809088 & 1.544966 \\ \mathrm{~N} & -2.602299 & 3.561565 & 0.165492 & \mathrm{H} & -3.306033 & 1.469634 & -1.370572 \\ \mathrm{C} & -0.745244 & -2.834967 & -0.022660 & \mathrm{H} & -2.233522 & -0.708745 & -1.414334 \\ \mathrm{C} & 0.017107 & -1.525011 & -0.026147 & \mathrm{H} & -1.781000 & 4.436568 & 1.893592 \\ \mathrm{C} & -0.706369 & -0.219402 & 0.021085 & \mathrm{H} & -2.545020 & 5.551176 & 0.761910 \\ \mathrm{C} & -0.228108 & 0.804986 & 0.843918 & \mathrm{H} & -0.942479 & 4.877292 & 0.391092 \\ \mathrm{C} & -0.832441 & 2.053384 & 0.889840 & \mathrm{H} & -3.190100 & 3.840153 & -1.863249 \\ \mathrm{C} & -1.970917 & 2.331433 & 0.106427 & \mathrm{H} & -3.970437 & 4.889798 & -0.659667 \\ \mathrm{C} & -2.448485 & 1.301232 & -0.731245 & \mathrm{H} & -4.444523 & 3.196708 & -0.782612 \\ \mathrm{C} & -1.832741 & 0.059017 & -0.760604 & \mathrm{H} & -2.506848 & -4.502129 & 0.975640 \\ \mathrm{C} & -1.925925 & 4.657061 & 0.831473 & \mathrm{H} & -2.637043 & -4.451862 & -0.784612 \\ \mathrm{C} & -3.594342 & 3.883232 & -0.841372 & \mathrm{H} & -4.921401 & -4.389264 & 0.275792 \\ \mathrm{C} & -2.838649 & -3.889911 & 0.131949 & \mathrm{H} & -4.596842 & -2.881037 & -0.599202 \\ \mathrm{C} & -4.293983 & -3.495468 & 0.251802 & \mathrm{H} & -4.463275 & -2.926268 & 1.168383 \\ \mathrm{C} & 3.399007 & -0.562267 & -0.069872 & \mathrm{H} & 1.856993 & 0.800172 & -0.681016 \\ \mathrm{C} & 2.908146 & 0.689336 & -0.439392 & \mathrm{H} & 3.403205 & 2.743328 & -0.789519 \\ \mathrm{C} & 3.784509 & 1.768364 & -0.503361 & \mathrm{H} & 5.815225 & 2.450739 & -0.275691 \\ \mathrm{C} & 5.138606 & 1.605108 & -0.219400 & \mathrm{H} & 6.672390 & 0.204073 & 0.351604 \\ \mathrm{C} & 5.619208 & 0.344077 & 0.130959 & \mathrm{H} & 5.123759 & -1.723277 & 0.493041\end{array}$


TS-R (Transition state for thermal isomerization of DMA-PHA from $Z$ configuration to $E$ configuration through out-of-plane rotation about the $\mathrm{C}=\mathrm{N}$ bond)

\section{Energy: -1012.77004258}

$\begin{array}{llllllll}\mathrm{O} & 0.937091 & 3.102514 & 0.098542 & \mathrm{C} & -4.029328 & -1.008852 & -1.401884 \\ \mathrm{O} & -1.311462 & 3.117816 & 0.140924 & \mathrm{H} & -1.759430 & 0.204509 & -1.301362 \\ \mathrm{~N} & -1.450090 & 0.467467 & 0.693166 & \mathrm{H} & -0.204657 & -1.554236 & 0.852675 \\ \mathrm{~N} & -2.125535 & 0.035012 & -0.367690 & \mathrm{H} & 1.611819 & -3.144447 & 0.673451 \\ \mathrm{~N} & 4.125883 & -2.583908 & -0.088239 & \mathrm{H} & 4.236516 & 0.045395 & -0.604339 \\ \mathrm{C} & -0.265986 & 2.493623 & 0.184421 & \mathrm{H} & 2.417237 & 1.615660 & -0.421516 \\ \mathrm{C} & -0.206747 & 1.036985 & 0.335740 & \mathrm{H} & 3.601321 & -4.109963 & 1.278946 \\ \mathrm{C} & 0.930166 & 0.177091 & 0.228736 & \mathrm{H} & 4.845174 & -4.526331 & 0.088884 \\ \mathrm{C} & 0.767665 & -1.204952 & 0.522870 & \mathrm{H} & 3.149290 & -4.429941 & -0.408966 \\ \mathrm{C} & 1.801082 & -2.107621 & 0.424670 & \mathrm{H} & 5.423508 & -1.680862 & -1.490948 \\ \mathrm{C} & 3.093579 & -1.695073 & 0.014392 & \mathrm{H} & 6.124957 & -2.972622 & -0.504778 \\ \mathrm{C} & 3.268962 & -0.320374 & -0.283373 & \mathrm{H} & 5.837018 & -1.378079 & 0.210026 \\ \mathrm{C} & 2.231212 & 0.579145 & -0.178551 & \mathrm{H} & 0.372591 & 4.965629 & 0.789914 \\ \mathrm{C} & 3.913962 & -3.981639 & 0.235831 & \mathrm{H} & 0.310446 & 4.763081 & -0.962538 \\ \mathrm{C} & 5.441974 & -2.124850 & -0.488819 & \mathrm{H} & 2.341368 & 6.093738 & -0.289395 \\ \mathrm{C} & 0.891491 & 4.525568 & -0.066608 & \mathrm{H} & 2.817566 & 4.557446 & -1.035376 \\ \mathrm{C} & 2.321754 & 5.007925 & -0.172001 & \mathrm{H} & 2.882696 & 4.745532 & 0.727864 \\ \mathrm{C} & -3.353923 & -0.606508 & -0.242938 & \mathrm{H} & -3.372281 & -0.533051 & 1.902481 \\ \mathrm{C} & -3.907803 & -0.855722 & 1.018377 & \mathrm{H} & -5.561771 & -1.697256 & 2.082726 \\ \mathrm{C} & -5.133002 & -1.506095 & 1.104083 & \mathrm{H} & -6.768234 & -2.417767 & 0.035157 \\ \mathrm{C} & -5.812610 & -1.911292 & -0.043772 & \mathrm{H} & -5.770476 & -1.966122 & -2.197470 \\ \mathrm{C} & -5.252134 & -1.657781 & -1.295308 & \mathrm{H} & -3.593373 & -0.810431 & -2.377014\end{array}$


$S_{1}$-min- $Z$ (the local minimum on $S_{1}$ state of DMA-PHA-Z corresponding to the emissive state)

\section{Energy: -1012.72869375}

$\begin{array}{llll}\text { O } & 0.563550 & 2.861713 & 0.138828\end{array}$

O $\quad-1.631592 \quad 2.631619 \quad-0.296941$

$\begin{array}{llll}\mathrm{N} & -1.301191 & -0.263578 & -0.074752\end{array}$

$\mathrm{N} \quad-2.539135 \quad 0.222858 \quad-0.013541$

$\mathrm{N} \quad 4.743360 \quad-1.957144 \quad 0.017701$

C $\quad-0.525625 \quad 2.089951 \quad-0.114859$

$\begin{array}{llll}\text { C } & -0.286691 & 0.659133 & -0.094119\end{array}$

C $\quad 1.023229 \quad 0.049878 \quad-0.073118$

C $\quad 1.125678 \quad-1.343768 \quad 0.217467$

$\begin{array}{llll}\text { C } & 2.330882 & -2.002467 & 0.252016\end{array}$

$\begin{array}{llll}\text { C } & 3.544560 & -1.318917 & -0.021418\end{array}$

$\begin{array}{llll}\text { C } & 3.453524 & 0.063473 & -0.351516\end{array}$

$\begin{array}{llll}\text { C } & 2.244825 & 0.713786 & -0.377796\end{array}$

$\begin{array}{llll}\text { C } & 4.805148 & -3.370832 & 0.345892\end{array}$

$\begin{array}{llll}\text { C } & 5.968862 & -1.236487 & -0.282358\end{array}$

$\begin{array}{llll}\text { C } & 0.331762 & 4.272530 & 0.141495\end{array}$

$\begin{array}{llll}\text { C } & 1.664417 & 4.940751 & 0.404034\end{array}$

C $\quad-3.623936 \quad-0.604203 \quad-0.010322$

C $\quad-4.915336$

$-0.031248 \quad 0.019820$

$\begin{array}{llll}\mathrm{H} & -2.650228 & 1.247733 & -0.065309\end{array}$

H $\quad 0.214394$

$-1.886716$

0.431923

H 2.342220

$\begin{array}{ll}-3.058823 & 0.490325\end{array}$

H 4.346746

$0.621820 \quad-0.602015$

$\mathrm{H} \quad 2.228371$

$\begin{array}{ll}1.759060 & -0.649155\end{array}$

H 4.383911

$\begin{array}{ll}-3.562860 & 1.338825\end{array}$

H 5.845052

$\begin{array}{ll}-3.691659 & 0.344784\end{array}$

H 4.254468

$\begin{array}{ll}-3.972844 & -0.385926\end{array}$

H 5.959842

$-0.843415 \quad-1.305158$

H 6.813153

$\begin{array}{ll}-1.915908 & -0.182927\end{array}$

H 6.114493

$-0.400136$

0.409913

H $\quad-0.403805$

$\begin{array}{ll}4.513558 & 0.915207\end{array}$

H $\quad-0.093901$

4.573579

$-0.820657$

H 1.538307

6.025338

0.439028

H 2.379221

4.701277

$-0.387389$

H 2.078585

$4.607340 \quad 1.358392$

$\begin{array}{llll}\text { C } & -3.482809 & -2.009794 & -0.028346\end{array}$

H $\quad-2.487973$

$\begin{array}{ll}-2.436065 & -0.058366\end{array}$

C $\quad-4.618484 \quad-2.804911 \quad-0.014080$

H $\quad-4.507224$

$\begin{array}{ll}-3.885046 & -0.029175\end{array}$

C $\quad-5.895839 \quad-2.241203$

H $\quad-6.775222$

$\begin{array}{ll}-2.875805 & 0.029679\end{array}$

C -6.030934

0.018301

H $\quad-7.018864$

$\begin{array}{ll}-0.398714 & 0.059206\end{array}$

$\begin{array}{llll}\mathrm{H} & -5.017850 & 1.050234 & 0.031372\end{array}$ 
$S_{1}$-min- $E$ (the global minimum on $S_{1}$ state of DMA-PHA)

\section{Energy: -1012.76676934}

$\begin{array}{llllllll}\mathrm{O} & -0.897035 & 3.103119 & -0.087417 & \mathrm{C} & 4.027187 & -0.972157 & 1.414702 \\ \mathrm{O} & 1.345157 & 3.097055 & -0.259696 & \mathrm{H} & 1.776835 & 0.256471 & 1.285505 \\ \mathrm{~N} & 1.447357 & 0.438496 & -0.707936 & \mathrm{H} & 0.174787 & -1.567965 & -0.888333 \\ \mathrm{~N} & 2.124052 & 0.044053 & 0.356127 & \mathrm{H} & -1.655663 & -3.138190 & -0.684815 \\ \mathrm{~N} & -4.155016 & -2.548664 & 0.102612 & \mathrm{H} & -4.228537 & 0.082641 & 0.613982 \\ \mathrm{C} & 0.293143 & 2.482197 & -0.238484 & \mathrm{H} & -2.392651 & 1.630394 & 0.410593 \\ \mathrm{C} & 0.218689 & 1.026167 & -0.368930 & \mathrm{H} & -3.656115 & -4.080277 & -1.267616 \\ \mathrm{C} & -0.932733 & 0.173888 & -0.254645 & \mathrm{H} & -4.899805 & -4.481158 & -0.072051 \\ \mathrm{C} & -0.788001 & -1.205140 & -0.547325 & \mathrm{H} & -3.200047 & -4.407362 & 0.417888 \\ \mathrm{C} & -1.832322 & -2.099317 & -0.435994 & \mathrm{H} & -5.422806 & -1.623969 & 1.518733 \\ \mathrm{C} & -3.112310 & -1.672538 & -0.012851 & \mathrm{H} & -6.150739 & -2.915078 & 0.551624 \\ \mathrm{C} & -3.268871 & -0.295640 & 0.284219 & \mathrm{H} & -5.859582 & -1.327947 & -0.177822 \\ \mathrm{C} & -2.220896 & 0.591319 & 0.167293 & \mathrm{H} & -0.363786 & 4.955689 & -0.830463 \\ \mathrm{C} & -3.962254 & -3.948258 & -0.222762 & \mathrm{H} & -0.194435 & 4.768840 & 0.916991 \\ \mathrm{C} & -5.460017 & -2.073928 & 0.519594 & \mathrm{H} & -2.254410 & 6.107574 & 0.358537 \\ \mathrm{C} & -0.831270 & 4.526913 & 0.060930 & \mathrm{H} & -2.692441 & 4.581577 & 1.147687 \\ \mathrm{C} & -2.248885 & 5.020595 & 0.250513 & \mathrm{H} & -2.866427 & 4.753514 & -0.610143 \\ \mathrm{C} & 3.346436 & -0.618005 & 0.245390 & \mathrm{H} & 3.338839 & -0.644420 & -1.899436 \\ \mathrm{C} & 3.881784 & -0.931352 & -1.007660 & \mathrm{H} & 5.515558 & -1.840037 & -2.047653 \\ \mathrm{C} & 5.099183 & -1.598669 & -1.074806 & \mathrm{H} & 6.735963 & -2.476543 & 0.018652 \\ \mathrm{C} & 5.786578 & -1.956849 & 0.083718 & \mathrm{H} & 5.766627 & -1.910307 & 2.237210 \\ \mathrm{C} & 5.242205 & -1.638986 & 1.326890 & \mathrm{H} & 3.603238 & -0.723463 & 2.383464\end{array}$


$S_{0}$-min (the $S_{0}$ minimum of PHA-Z)

\section{Energy: -878.929504933}

$\begin{array}{llll}\mathrm{O} & -2.422110 & -1.578995 & 0.118578 \\ \mathrm{O} & -0.368453 & -2.444184 & -0.095980 \\ \mathrm{~N} & 1.598484 & -0.685402 & -0.049631 \\ \mathrm{H} & 1.345785 & -1.671266 & -0.068220 \\ \mathrm{~N} & 0.650066 & 0.222521 & -0.056438 \\ \mathrm{C} & -0.618281 & -0.065475 & -0.061469 \\ \mathrm{C} & -1.102067 & -1.469411 & -0.027790 \\ \mathrm{C} & -1.548873 & 1.094184 & -0.042107 \\ \mathrm{C} & -2.740202 & 1.107134 & -0.777348 \\ \mathrm{H} & -3.023738 & 0.237198 & -1.358548 \\ \mathrm{C} & -3.559439 & 2.231718 & -0.773686 \\ \mathrm{H} & -4.476552 & 2.227035 & -1.354079 \\ \mathrm{C} & -3.204229 & 3.360282 & -0.038787 \\ \mathrm{H} & -3.846614 & 4.234894 & -0.035253 \\ \mathrm{C} & -2.018055 & 3.358304 & 0.691649 \\ \mathrm{H} & -1.733091 & 4.231010 & 1.270670 \\ \mathrm{C} & -1.198470 & 2.235102 & 0.690271 \\ \mathrm{H} & -0.275614 & 2.227419 & 1.261370 \\ \mathrm{C} & -2.940669 & -2.920528 & 0.177563 \\ \mathrm{H} & -2.487389 & -3.431786 & 1.031454 \\ \mathrm{H} & -2.641187 & -3.452265 & -0.729856 \\ \mathrm{C} & -4.442629 & -2.808811 & 0.307798 \\ \mathrm{H} & -4.866565 & -2.290535 & -0.555300 \\ \mathrm{H} & -4.710404 & -2.257678 & 1.211694 \\ \mathrm{H} & -4.883210 & -3.806580 & 0.364804 \\ \mathrm{C} & 2.942868 & -0.296066 & -0.041964 \\ \mathrm{C} & 3.319128 & 1.050297 & -0.038704 \\ \mathrm{H} & 2.553601 & 1.816555 & -0.045871 \\ \mathrm{C} & 4.669617 & 1.378460 & -0.029667 \\ \mathrm{H} & 4.958096 & 2.424939 & -0.027769 \\ \mathrm{C} & 5.649383 & 0.387074 & -0.024318 \\ \mathrm{H} & 6.700340 & 0.654733 & -0.017911 \\ \mathrm{C} & 5.263984 & -0.951454 & -0.028236 \\ \mathrm{H} & 6.014029 & -1.735935 & -0.024486 \\ \mathrm{C} & 3.917919 & -1.297580 & -0.036829 \\ \mathrm{H} & 3.617263 & -2.341513 & -0.039255\end{array}$


$S_{0}-$ min-P-E (the $S_{0}$ minimum of PHA-E)

\section{Energy: -878.924067369}

$\begin{array}{llll}\mathrm{O} & 2.921297 & -1.128357 & -0.235701 \\ \mathrm{O} & 1.262716 & -2.649887 & -0.311661 \\ \mathrm{~N} & -1.453940 & 0.310577 & -0.027513 \\ \mathrm{H} & -1.193653 & 1.292746 & -0.056408 \\ \mathrm{~N} & -0.527904 & -0.627594 & -0.098193 \\ \mathrm{H} & 2.319832 & 0.963204 & -1.927276 \\ \mathrm{C} & 1.630624 & -1.500743 & -0.237268 \\ \mathrm{C} & 0.725024 & -0.315984 & -0.134131 \\ \mathrm{C} & 1.261113 & 1.070943 & -0.059126 \\ \mathrm{C} & 0.947011 & 1.879635 & 1.039976 \\ \mathrm{H} & 0.337836 & 1.475281 & 1.844528 \\ \mathrm{C} & 1.423884 & 3.185756 & 1.114899 \\ \mathrm{H} & 1.177693 & 3.800322 & 1.974604 \\ \mathrm{C} & 2.219761 & 3.695598 & 0.092919 \\ \mathrm{H} & 2.593620 & 4.712657 & 0.150675 \\ \mathrm{C} & 2.539856 & 2.895163 & -1.002803 \\ \mathrm{H} & 3.163237 & 3.288498 & -1.799224 \\ \mathrm{C} & -2.811082 & -0.030900 & -0.023584 \\ \mathrm{C} & -3.223194 & -1.366804 & -0.019656 \\ \mathrm{H} & -2.477544 & -2.152332 & -0.028235 \\ \mathrm{C} & -4.582117 & -1.657751 & -0.005873 \\ \mathrm{H} & -4.898121 & -2.696204 & -0.003184 \\ \mathrm{C} & -5.535009 & -0.640564 & 0.005244 \\ \mathrm{H} & -6.592778 & -0.879422 & 0.016584 \\ \mathrm{C} & -5.113163 & 0.686631 & 0.001582 \\ \mathrm{H} & -5.841320 & 1.491435 & 0.009418 \\ \mathrm{C} & -3.757963 & 0.996848 & -0.012862 \\ \mathrm{H} & -3.431094 & 2.033104 & -0.016794 \\ \mathrm{C} & 3.881247 & -2.196543 & -0.303532 \\ \mathrm{C} & 4.080905 & -2.833431 & 1.058659 \\ \mathrm{H} & 4.795562 & -1.721399 & -0.662307 \\ \mathrm{H} & 3.540545 & -2.930545 & -1.037218 \\ \mathrm{H} & 4.856977 & -3.600636 & 0.998801 \\ \mathrm{H} & 4.390174 & -2.082580 & 1.789488 \\ \mathrm{H} & 3.154300 & -3.301288 & 1.396143 \\ \mathrm{C} & 2.064028 & 1.590852 & -1.079570\end{array}$


$S_{1}$-min (the global minimum on $S_{1}$ state of PHA)

\section{Energy: -878.851153510}

$\begin{array}{llll}\mathrm{O} & 2.795265 & -1.428624 & -0.440323 \\ \mathrm{O} & 0.789884 & -2.457620 & -0.445883 \\ \mathrm{~N} & -1.319452 & -0.207695 & 0.336951 \\ \mathrm{H} & -0.919096 & -0.351391 & 1.257754 \\ \mathrm{~N} & -0.534663 & -0.124999 & -0.722208 \\ \mathrm{H} & 3.374898 & 0.453666 & 0.520925 \\ \mathrm{C} & 1.448630 & -1.434859 & -0.426766 \\ \mathrm{C} & 0.822509 & -0.102416 & -0.404607 \\ \mathrm{C} & 1.457071 & 1.177262 & -0.174163 \\ \mathrm{C} & 0.699077 & 2.348138 & -0.405089 \\ \mathrm{H} & -0.310211 & 2.253181 & -0.787763 \\ \mathrm{C} & 1.236188 & 3.605964 & -0.172121 \\ \mathrm{H} & 0.636605 & 4.488701 & -0.368597 \\ \mathrm{C} & 2.538004 & 3.736284 & 0.306055 \\ \mathrm{H} & 2.958855 & 4.719656 & 0.487908 \\ \mathrm{C} & 3.297641 & 2.590733 & 0.550432 \\ \mathrm{H} & 4.309133 & 2.684379 & 0.932219 \\ \mathrm{C} & -2.710430 & -0.202899 & 0.216523 \\ \mathrm{C} & -3.320445 & -0.058185 & -1.032639 \\ \mathrm{H} & -2.701855 & 0.038248 & -1.916084 \\ \mathrm{C} & -4.708110 & -0.049103 & -1.109857 \\ \mathrm{H} & -5.181693 & 0.062232 & -2.079929 \\ \mathrm{C} & -5.491016 & -0.181643 & 0.035467 \\ \mathrm{H} & -6.572792 & -0.173777 & -0.036634 \\ \mathrm{C} & -4.870245 & -0.325738 & 1.275097 \\ \mathrm{H} & -5.466695 & -0.430519 & 2.175459 \\ \mathrm{C} & -3.484792 & -0.337386 & 1.372731 \\ \mathrm{H} & -3.001109 & -0.451467 & 2.338648 \\ \mathrm{C} & 3.427299 & -2.719855 & -0.433507 \\ \mathrm{C} & 3.456826 & -3.307486 & 0.964503 \\ \mathrm{H} & 4.433574 & -2.532505 & -0.811379 \\ \mathrm{H} & 2.896175 & -3.375135 & -1.127108 \\ \mathrm{H} & 3.998956 & -4.256328 & 0.956844 \\ \mathrm{H} & 3.960608 & -2.626832 & 1.655326 \\ \mathrm{H} & 2.441194 & -3.490931 & 1.319952 \\ \mathrm{C} & 2.775304 & 1.329128 & 0.316093\end{array}$

